\title{
II.
}

\section{Erworbene Zwerchfellshernien.}

Bearbeitet und mit neuen Fällen vermehrt

ron

Dr. August Popp,

Assistent der chirurgischen Klinik des Prof. Dr. ron Nussbaum in München.

Viele Chirurgen behaupten: dass Zwerchfellshernien nur auf dem Leichentische, nie aber am Krankenbette diagnosticirt werden könnten und das Studium derselben daher für den Praktiker keinen Werth habe.

Zwei im städtischen Krankenhause zu Mïnchen (links der Isar) beobachtete Fälle haben mir aber die freudige Ueberzeug'ung verschatft, dass manchmal eine Wahrscheinlichkeitsdiagnose doch auch am Krankenbette gemacht werden kann, und das nähere Studium lässt mir auch möglich erscheinen, dass eine solche Diagnose zum Nutzen des Kranken gemacht werde, weshalb ich diese beiden Fälle mit Vergniigen mittheile, und Herrn Geheimrath von Gietl und Herrn Director Lindwurm, welche mir dazu guitigst ibre Erlaubniss gaben, hierfuir bei dieser Gelegenheit meinen verbindlichsten Dank ausspreche.

Den bezüglichen Krankheitsgeschichten und Sectionsberichten werde ich die in der Literatur aufgefundenen Fälle voranschicken und am Schlusse eine tabellarische Zusammenstellung nach eiuigen Gesichtspunkten hin anfiugen.

Die Mehrzahl der anzuführenden Fälle entnelıme ich der Dissertation von Dreifus (uiber die Brüche des Zwerchfells); eine Reihe von Fïllen fand ich in verschiedenen Jahrgängen von Schmidt's Jahrbtichern der gesammten Medicin. 
1) Glandorp bobachtete den Fill, dass bei einem soldaten eine Wunde die Oeffintng fitr die speiserölire im zwerchtell gatroffen and erweitert hatte, durch sie stieg der linke Theil des Magens mit einem Theile des Zwolffingerdims nud Colons nach oben. Der Verwudete starb unter schmerzen, Blutung, tiefer Ohnmaclit mit Unterbrechng des Athmens und sehluclizen.

2) Ein 25 jähriger Mam erlielt zwei Wunden durch einen Degen, die eine migefihn vier Querfinger breit unter dem Schwertknorpel, mehr links von der Gegend der 4 . und 5 . muteren Rippe ans, die andere etwas unter dem linken Hypochondrium. Durch beide Wunden drang das Netz lierans. Nach geschehener Verletzung ging dor Verletzte nach Hanse, wurde aber, da er vor schwaiche lamm stehen konnte, in das Hospital gebracht. Hier drohten, so oft er sich niederzulegen versuchte, Erstickungsaufille, weshalb er mit aufgerichtetem Halse zil athmen genöthigt war. Erbrechen gesellte sich hinzu, olne dass der Verwundete etwas zu sich nahm. Dreizehn Stmden nach geschehener Verwundung starb er.

Bei der Oefinmong der Brust- und Batwhhöhle zeigte sich mässiger Bluterguss. Die muterste Wunde war in die Bauchhöhle eingedrungen, hatte aber kein Eingeweide getroffen. Die ohere Wunde dagegen hatte Brust- und Batcheingewoide verletat; nïmlich doppelt den obem Theil des Magens, und auf ziemliche Strecke das Zwerchfell dnrehbohrt, zugleich aber anch noch den untersten Theil des linken Lungenlappens eingeschnitten. Dureh den Schnitt im Zwerchfell war der Magen mit einem Theile des Netzes in die Brusthöhle eingedrungen.

3) Bei Parens findet sich folgender Fall. Fin Stich ging mitten durch das Zwerelfell hindurch und tïdtete 3 Tage nach der Verwundung. „Als ich", sagt Pareus, ,bei der Ocffinng den Magen nicht im Unterleibe fand, kam mir dies selır räthselhaft ror; ich suchte nach und fand ihn endlich in der Brust, abwohl die Wunde im Zwerchfell nicht ibber einell Daumen gross war."

4) Ein andermal war die Verwundung des Zwerchfelles so beschaffen, dass der ganze Magen voll von Speisen und Getränken mit dem Pankreas, Netz und Colon in die linke Seite gedrungen war, so dass die Lunge dieser Seite ganz zuriekgedrängt wurde. Die Oeffinmg. im Zwerehfell war 4 Finger breit lang. Was die begleitenden Symptome betrifft, so muss bemerkt werden, dass der Verletzte zuerst iiber Schmerz in der Cardia klagte, und alle Speisen, Getrinke und Arzneien sogleich wieder wegbrach, sodass er 3 Tage und 8 Stunden nach der Verletzung seinen Geist aufgab.

5) Es wurde Einem zwischen die 4. und 5. Rippe ein Messer gestossen. Nach Stägiger Behantlung, nachdem er von Husten, von schwerer Respiration ma anderen Symptomen ganz frei geworden war, so, dass er die hälnslichen Geschïfte wieder verrichten konnte, wurde er am 9. Tage, wo er sich und dem Arzte gesund vorkann, ohnmächtig und starb nach einem sehr beschwerlichen und tiefen Athmen in der 24. Stmde. Beim Oefonen des Leichnams fand man die dunten Gedarme durch eine änserst enge Wunde des Zwerchfells in die Brnst gedrungen.

(b) Ans einor kleinen Wunde, die ein Menseh unter der linken Brust zwischen der letzten wahren und crsten falsehen Rippe bekommen hatte, 


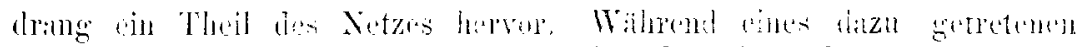

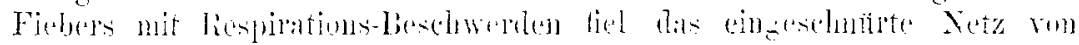

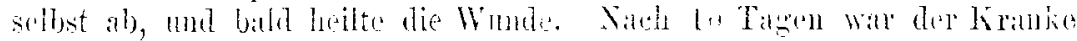

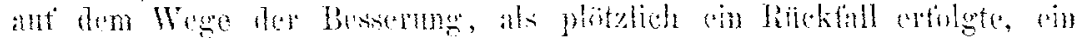

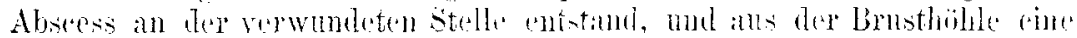

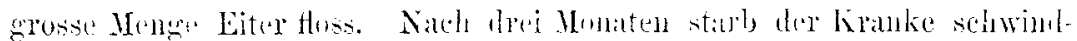

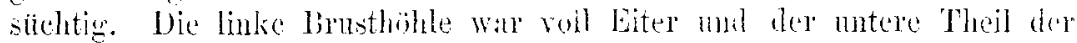

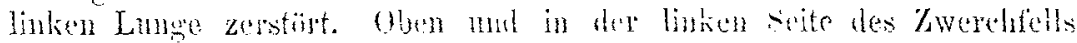

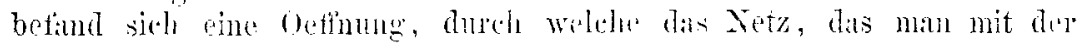

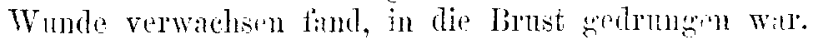

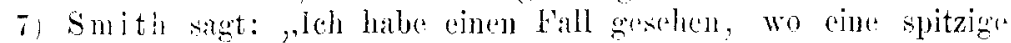

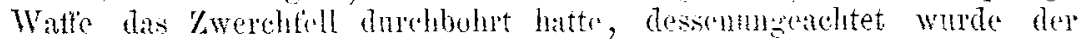
Patient schuell und allem Anschein nath volliummen hergestellt. Nach drei Monaten starb er an cinem cingeklemmten bruche des Magens, dex durch das Zwerchifell in die Brust gedrungen war."

s) Ein Studirender stiess sich in cinem Anfalle von Melancholie das Schwert so zwischen die 1. nnd 5. Rippe, dass es am Riucken an der 9. wieder zum Vorschein kim; nach zwei Monaten war die YVunde geheilt und der Irensch schien gesund. Nach fiünf Monaten aber bekam er wicder einen Anfall, bei welehem er alles Genossene erbrechen musste; später stelle sich ein Erbrechen von grünlicher Galle mel zuletzt von einer grossen Menge schwarzen Stoffes ein, so dass el nach fünf Tagen unter kalten Schweissen und anderen Symptomen seinen Geist atmohanchte. Beim Oefinen des Küpers find man die Wunde im selmigen Theile des Zwerchmuskels. In der linken verletzten Seite traf man beinahe keine Lung melur. Olme Zweifel war sie verdorben mit dem Eiter weggeworfen worden. Nur ein kleiner Theil dersclben war mit den Rippen verwachsen. Der ganze Magen stieg in die linke Seite der brust; dals Herz mit scinem bentel war grom die rechte Seite hingctricben, wo man bald nach erhaltener Wunde anch den Herzschlag beobachten kom te; das Ierz wiu trocken, klein und zusammengeschrumpit, wihrend sein Beutel Wasser enthielt. Netz und Pankreas überdeckten beinahe den ganzen Magen.

(1) Nach Guillement war in einem Falle cin grosser Theil vom Colon durch eine kanm cinen kleinen Finger grosse Wunde im Heischigen Theile des Zwerchfulles in die Brusthöhle cingedrungen. Nach der Verwundung hatten sich geraume Zeit blos des Abonds bauchsehmerzen ringestellt, die joloch $i m$ S. Monat durch ihre Ireftigkeit den Menschen tödteten. 11) W. G. ein Mensch, ungefalu 10 Jahre alt, dem Gommsse des Weines sehr ergeben, ward eincs Tages bald nach dem Essen von heftigen Schmerzen befallen, welche er im Epigastritm zu fïhlen glanbte, ihnen folgte unmittelbar Uebclsein und Erbrechen. Ungefïh (ine halbe Stunde nach Beginn des Anfalles fing er an, bei fortlauernder Neigung zum Erbrechen, sich über Kälte und Schaudern zu beklagen. Der Schmerz in der Magengegend war nicht mehr so heftig, als im Anfung, auch wurde er durch Druck in die Magengegend nicht anfiallend verstärkt. Der Bauch war nicht gespannt, sondern im Gegentheile bemerkte man eine anffallende Leere und Ziehen in der Nabelgegend. Er beschwerte sich selir iber burst, seine Zunge war trocken und aufge- 
sprungen wi latte eine lielle, glinzenite Farbe. Er crzihlte, or habe an dem nämlichen Norgen rinen regelmäsigen Stuhlgang gehabt. Seine Hant war heiss und trocken, die Temp. 95 Fahrenheit, sein Puls roll und hart und schlu. aig mal in de! Minnte. Obgleich dieso Symptome ein wenig verschieden waren ron demen bei Gastritis oder Gastroenteritis, so waren doch so dentliche Zeichen daron rorhandem, dass sie bestimnten, durch ein energisches Verfahren gegen den heimtückischen Charakter dieser Leiden zu schiitzen. Es wurden 26. Inzen Blut aus dem Arme gclassen und mit der Entlenrung wiurde noch fortgefalneen worden sein, hätte nicht ein Himneigrn zur Ohnmacht zum Aufhören bewogen. Der Kranke wurde in ein lanes Bad gebracht, erhielt eine Cnze Oleum Ricini nnd ein starkes Klystier. Das Oel wurde sogleich wieder weggebrochen, aber nach dem bade bekam er zwei copiöse Stuhl-Auslecrungen; nachher war der Schmerz nicht merklich rermindert, und die geringste Menge ron Flüssigkeit, die in den Magen gebracht wurde, brach er im Angenblicke wieder weg. So danerte es die ganze Nacht hindurch, gegen Norgen hatte er wieder einen Stuhlgang. Er schien munter und sagte, er habe keine Schmerzen.

Doch konnten diese Symptome nicht tänschen. Sein Puls war kaum zu fülllen, kalte Schweisstropfen befeucliteten seine Stirne, sichere Zeichen äes mahen 'Todes, der bald nachher erfolgte.

Resultate der Scetion. Beim Oeffnen des Banches zeigte sich eine ausserordentliche Lageveränderung der Theile; zuerst stellte sich der Magen dar, durch Flüssigkeit zu ciner enormen Grösse ansgedehnt und beinahe die ganze Höhle des Lnterleibes ausfüllend. $\mathrm{Er}$ schien etwas ron seiner natïrlichen Lage weggezogen zu sein und war so sehr dem Schambeine genähert, dass die Finger kaum dazwisclen durchdringen komnten. Mit Aissnalime weniger kleiner rother Punkte auf der Aussenfliche zeigte der Magen keine Zeichen ron Entzüudung. Als nun der Magen aufgehoben wurde, zcigte das Zwcrchfell eine convexe Fläche gegen den Bauch, es war sehr gespannt und es zeigte sich, dass die ganze Masse der Eingeweide, welche nicht durch das Mesenterium enge an die Wirbelsänle geheftet sind, durch eine widernatïrliche Oeffnung in Heischigen Theile des Zwerchfells in dessen linke Seite getreten war. Der Thorax entlielt eine Flissigkeit, die olme Zweifel fon der weiten Oberfläche der entzündeten Eingeweide secernirt war. Im Bauch wurde dagegen nichts von der Art gefunden, der Austritt der Flüssigkeit ans dem Thoras wurde ohne Zweifel durch den Druck der Theile anf die Oeffnung, indem sie nach Art eincr Klappe wirkte, verhindert. Beide Lumgenlappen waren von blasser Farbe und mit kleinen purpurnen Flecken besetzt; dic linke Lunge war anf den dritten Theil ihrer natürlichen Grösse zusammengesclirumpft und in den obcrn Theil der Höhle gedrängt, da der untere Theil der Brusthühle durchans ron den dislocirten Eingeweiden erfïllt war. Das Duodenum zeigte kein Zeichen von Krankheit and hatte seine natiirliche Lage beibehalten, das Jejunum dagegen, das ganze Iletrm, $\$$ Zoll des letzteren ausgenommen, das Colon transversum waren dirch die widernatirliche Oeffnung eingedrungen. Diese Theile waren ron einer lividen blauten Farbe, aber von fester Textur. Einige Theile des Mesenterinm und des Mesocolon, welche Fett 
enthieltin, zeigten sorosse rothe mul livite Flecken. Die Geffnumg liens loicht zwei Fingre zu und das Notz, das abentalls durch dieselbe gredrungen nur fest an die anlegenden 'Theile geheftet war, schlang sich auf eine eigenthiumliche Weise nm das Colon und nmgab beinahe die canze Masse der voredrängten Gingeweide nach Art eines Sackes. Der

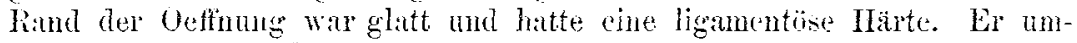
gab die Theile nicht so fest, dass el eine Einschnuirung der Gedimme verursachte, demn der Kanal der Eingreweide war durchaus frei. In der ganzen Cmgegend des Randes der Oefinmg wurden starke häntige Fortsatze ron beträchtlicher Länge bemerkt, die sich zur Plella costalis, zum Mediastioum wnd zu einem Theile der Eingeweide erstreckten und Verbindungen mit ihnen eingingen. Bei dem Versuche, die Eigenthümlichkeit dieser Erseheinungen zn erklüren, erimnorte man sich, dass dieser Mamn 11 Monate fiuher in seiner linken Seite zwischen der 6. und 7 . Rippe eine schief abwarts sich erstreckende Wunde erhalten hatte. Er war in das Hospital nach Mitternacht verbracht worden, eine kleine Portion einer gelben zelligen Hant war durch die Wunde vorgedrangt. Die Wunde wurde erweitert, um die Riückkehr des vorgefallenen Theiles zu erleichtern; nach wenigen Tagen war er aber geheilt, ohne dass ein schlimmes Symptom sich gezeigt hätte. Ohngefihr 7 Monate nach dieser Verletzung beklagte er sich iiber eine leichte Lnordnung der Eingeweide, von der er sich jedoch bald wieder erholte. Dies war das erstemal, dass er sich seit seiner Verwndung beklagt hatte. Von dieser Zeit an konnte er weniger Anstrengungen ertragen; er konnte nicht aufrecht stehen, ohne einige Linuhe zu fühlen, seine Respiration litt Noth, nnd selbst mässige Bewegungen wurden nur mit Schwierigkeit ertragren.

11) Nach Mare wurde aureh einen Messerstich in die Brust das Zwerchfell verletzt und der in die Wunde tretende Magen eingeklemmt. Von Zufällen stellten sich heftige Schmerzen in der Brust, Beklemmung, miihsames Athmen, Luvermögen anf einer Seite zu liegen und Erbrechen ein. Der Tod erfolgte nach 19 Stunden.

12) Bernhuber fand bei einem 43 jährigen Mann, der unter Einklemmungserscheinungen nach 30 Stunden gestorben war, ein 9 Fuss langes Stück Dünndarm in der linken Brusthöhle. Die linke Lnnge war comprimirt, luftleer und nach oben geschoben, das Herz, etwas nach rechts gedrängt, lag auf den Gedärmen. Die Bruchpforte fand sich mahe der Wirbelsänle links mit wulstigen, vermarbten Fíindern, nud dieser Stelle entsprechend war auf dem Fiucken eine von einer Stichwunde herriihrende Narbe.

13) Ein 45 jähriger Schuster bekam, nachdem er vor 1 Jalre zuweilen heftigen Schmerz in der linken Regio hypochondriaca und trockenen Husten gehabt hatte, eines Tages Brechen mit ïberhandnehmender Dyspnoë. Den folgenden Tag klagte er iber heftigen Schmerz in linken Hypochondrinm, die Dyspnoë war dieselbe. Im Gesicht Zeichen von Angst, Puls intermittirend, kaum fühlbar; Extremititen kalt, Lippen livid. Percussionston über die ganze linke Brusthälfte dumpf. Respirationsgemurmel hier unhörbar, anf der rechten Seite pueril. Die Herztöne vernahm man nur unter den Knorpeln der 4. und 6. Rippe. Vier Stunden nach seiner Aufnahme erfolgte der Tod. Die Section ergab Folgendes: 
Das IIerz war gesund und lag nur etwas zu sehr nach rechts. Dic rechte Lunge gesumd. In der linken Brnstlöhle fanden sich uiber sechs Pfund röthlicher Flïssigkeit, die linke, luftleere Lmoe lag zusammengedriickt an der Wirbelsaiule und an Rande des Speculum Helmontii an, mit welehem sie verwaclsen war. Die linke Inälfte des Ditphragma drängte gegen den Bauch herab nnd an einer seiner tiefen stellen nit seiner Fläche zusanmenhïngend kam eine dunkle, wciche Masse zum Vorschein. Es war, wie sich fand, ein Stiick Colon transversum mit einer bedentenden IIenge von grossem Netz in eine Oefonumg des Diaphlagma eingeschinürt, deren läuder callös waren. Aussen auf der Hant bemerkte man am untern Ende der linken Brust in der Mitte der Rippen eine $1 / 2$ Zoll lange Narbe, die durch den 9. Intercostalraum gerade hindurch bis ztu imern Oberfläche der Brust gelit. Ein Fortsatz von dem Theile des Netzes, der mit dem Colon in die Brust hineinragte, war tief in die Narbe mit eingewachsen. Die Oefthung im Zwerchfelle, welche, kanm drei Fingerspitzen weit, die Scllinge des Colon enthielt, lag zwischen der letzten Rippe und Pars tendinea des Diaphragma. Wie man später erfuhr, hat der Verstorbene 15 Monate vor seinem Tode in einem Streite an genannter Stelle eine Wunde mit einem Schusterpfriemen erhalten. Nach jener Zeit waren verschiedene Male Erkrankungen unter Symptomen von heftigem Ileus eingetreten, jedoch erfolgte stets anscheinend Genesung.

14) Die 25 jährige Kranke war als Kind in ein Messer gefallen, welches nnter der linken Brust bis an das Heft eingedrungen war und wahrscheinlich das Zwerchfell durchbohrt hatte. Eine Schlinge des Colon transversum und ein Theil des Netzes zeigten sich durch das Zwerchfell eingeklemmt und so fest verwachsen, dass sie nur durch das Messer getrennt werden konnten. Der Vorfall bestand deshalb wohl schon lange und war durch die nicht geschlossene Wunde veranlasst.

15) Im Monthly Jonm. 1541 findet sich verzeicbnet: ,Die Thäterin wurde von der Jury freigelassen, weil der Verwurdete (penetrirende Brustwunde) anscheinend genas, obgleich er oft ïber Schmerzen klagte im linken Hypochondrium. Nach Jahresfrist starb derselbe schnell an den Folgen der Einhiemmung. Die Zwerchfellshernie hatte ihren Sitz links.

16) Am 17. April 1552 starb in einem russischen Erziehungs: institute ein 14 jähriges Fräulein, dessen Schicksale und Todesart besonders bemerkenswerth erscheinen. Der Vater, Stabseapitain, befehligte eine Festung am Kaukasus, als diese von den Tscherkessen erstürmt wurde. Vater nud Mntter wurden getödtet, das zweijährige Kind erhielt mehrere Hieb- und Stichwunden, deren Narben noch jetzt an der Hand, dem Unterschenkel und namentlich der linken Brtsthälfte zwischen 5 . und 9. Rippe sichtbar waren. Die Tscherkessen nahmen das Kind mit in die Gefangenselıaft, von der es erst nach fünf Jahren durch Loskaufung von Verwandten befreit wurde. Vom siebenten Jalıe an befand sich das Fräulein als Kronzögling im fraglichen Institute. Während ihres Aufenthaltes klagte sie oft über Schmerzen an der linken Brusthäfte, zu denen sich nicht selten Uebelkeit und Erbrechen gesellte. Am 15. April trat plötzlich unter Erblassen stechender Brustschmerz auf, Lebelkeit und Erbrechen kam hinzu und am folgenden Tage waren die 


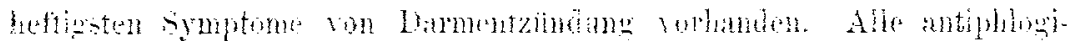

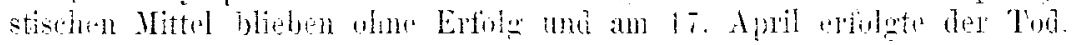

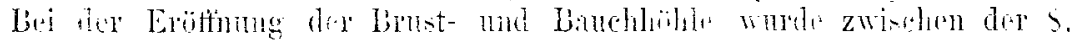

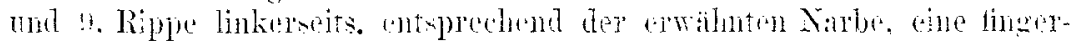

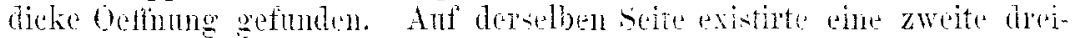

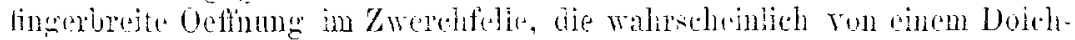

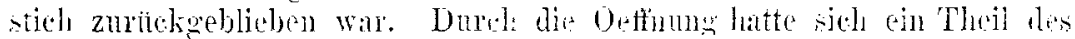

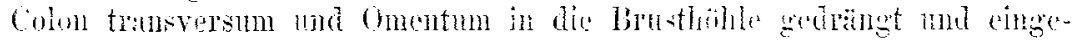

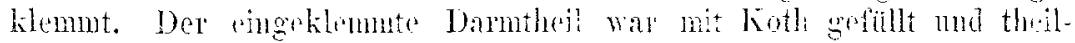

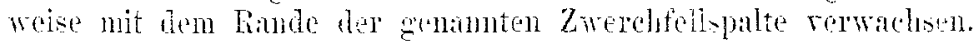

17) Ein Neger latte rinen Meserstich in the linke Sute der Brust ahalten, welcher durch das Zwerchfeli in die bauchhohle eingednungen

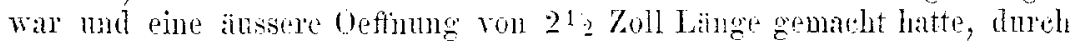
welehe ein 3 Zull langes nnd 2 Zoll dickes Netzstick leproprate. Als Spilnan den Veretzten zo Minuten spater sab, fand er ihn von deu

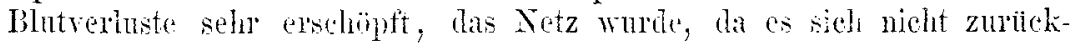
brimgen liess, abgeschnitten und ainige lose Näite ancelogt. Ausserdem

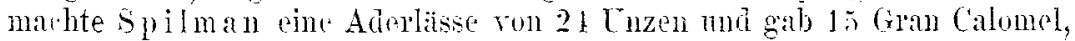
welche jedoch keinen stuhl herbeiführten. Erst nach wioderholten Flysticren und reichlicher Darrechmog ron Senma und Salz crofolenten am andern Tige dui rombliche Auslecrungen. Der buls war beschlennigt, die Temperatur ahöht, der Magen emplindlich; wiederholt stelle sich Frbrechen ein ineue Blutentzichung von eingen Lnzens. Au f. Tage zeigte sich der Kranke sehr erschüptt, das Gesicht ängstlich rerzogen, spitz; Puls 140, heftiger Durst, liartnäckige Obstipation, dagegen kein Schmerz nud keine Anftreiloung dos Leibes. Alle Mittel,

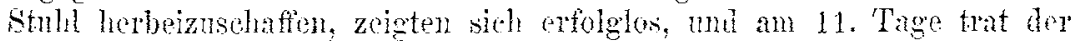
Tou cin. Bui der Section fand sich der Magen fast in seiner ganzen Ansdehnung in der Brusthöhle gelegen, mit der Herzspitze und der linken Lunge in numittelbarer Berührung, stark allogedehnt und wit bes eingeklemmtem Bruche in Folge gohinderter Cireulation und Ernährung dunkelbran gefübt, mit viel gevelhoser, schwarzoriner Flibsigkeit mul moreanderton speiseresten erfïllt. An der stelle, wo der Magen durch

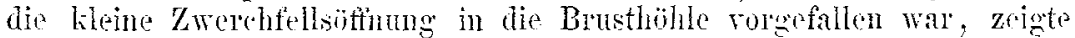
sich derselbe selur verengert mo der Pylorths gänzlieh verschlossen, so dass also die Crache der hartnäcligen Stuhlrerstopfung sowie ande des Todes klar zu Tage lag.

15) Ein Mann, welcher verschicdentliche Messerstiche in die linke seite der Brot erhalten hatte, zejgte namentlich zwei Wunden, durch welche die Sonde bis tief in die Brusthohle eindringen konnte. Trotzdem befand $\mathrm{cr}$ sich nach 24 stunden verhältnissmässig wohl, hatte neder Blutspucken, noch Husten oder Sclmenzen. Die Percussion ergab aut der verletzten Seite eine vermehrte Resonanz, da jedoch die Athmungsgeräusche bis nach unten hürbar blieben, so wurde die liesonanz ant eine Ansdelmung des Nagens bezogen. In den näclssten 2.4 Stunden warde wegen eintretender Schmerzen ein Tesientor erforderlich. Am 3. Tage stellte sich beträchtliche Dyspnoë ein, doch blich das Athmen noch immer bis in die nutersten Theile der Brust häbar. Lnter rasch zunehmenden Athembeschwerden verfiel der Kranke und starb an 5. Tage. 
Der Sectionsbefund gab eine genügende Erklärung für die Erscheinungen während des Lehens. Im Zwerchfell befanden sich zwei Oeffinungen, durch deren eine ein grosser Theil des Colon transversum in die Brusthöhle eingedrungen, während die andere, etwas kleinere, Oeffinung frei war. Rings um beide Wunden war das Bauchfell entzündet.

19) Ein 42 jahniger Schiffscapitain, von den man nach dem Tode erfuhr, dass er 6 Jahre zuror einen Selbstmordversuch gemacht latte, indem er mittels eines spitzen Messers dis Brust in 5. Intercostalranm durchbohrte, etwas nach innen von der Brustwarze, wnde unter Erscheinungen des Ilens anfgenommen. Eingeklemmter Bruch war nicht vorhanden. Tod mach 5 Tagen. Autopsie zeigte: Ileum hinter der Radix mesenterii emporgestiegen und durch einen 2 Finger breiten Spalt des Zwerchfells in die linke Pleurahöhle gelagert. Der Zwerchfellspalt war ron einem fibrösen abgerundeten Rande umgeben und lag dem 5 . Intercostalraum gegenüber nud in der Nähe der schrägen, der äusseren Hautuarbe entsprechenden Plenranarbe. Bei Eröftinung der Thoraxhöhle zeigte sich links ein grosser mit harten Fäcalmassen gefüllter Theil des Colon transversum und das ganze grosse Netz, ausserdem Abschnitte des Ileum, welche abgeschnürt erschienen. Bei Inspection der Bauchhöhle zeigte sich, dass ein Theil des Mesenterium so um seine Achse gedreht war, dass sich ein Volvulus im untern Theile des Jejunum gebildet hatte.

20) In bayr. ärztl. Intelligenzblatt befindet sich ein Bericht über eine Stichwunde von der Lendengegend ans in den Magen durch das Zwerchfell, die Lunge und den Herzbentel, wobei das Leben noch eine Zeit lang fortbestand. Ein 20 jälriger Hensch wurde in die linke Lende gestochen und schleppte sich noch eine Strecke weit fort, bis er ohnmächtig zusammenbrach, 14 Stunden nach der Verletzung erfolgte der Tod. Es zeigte sich eine Wunde im Blindsacke des Magens und zwar an der vordern und hintern Wand desselben, von hier ging der Stich in schiefer Richtung nach oben, durchdrang das Zwevchfell, den untern Lappen der linken Lunge und eröffnete den Herzbeutel, ohne das Herz selbst zu verletzen. Der verletzte Magenfundus war durch die Zwerchfellswunde als Hernie hindurchgestülpt und so war ein Theil des Mageninhaltes in die Pleura- und Pericardialhöhle hinein ergossen. Ein bedeutender Bluterguss, der wohl die nächste Todesursache, war aus der Fena lienalis md einzelnen Magenvenen, die durchschnitten waren, gekommen.

21) Ein Mädehen ron 19 Jahren wurde in die linke Brust geschossen, sie fiel ohnmächtig zu Boden, als sie wieder zum Bewusstsein gelangte, wurde sie ron häufigem Schluchzen befallen, sie hatte Neigung zum Erbrechen, bei den heftigsten Brust- und Bauchschmerzen; es erfolgte jedoch kein Erbrechen, wahrscheinlich wegen der grossen Schwäche und des Blutverlustes. Nar mit Mühe schöpfte sie Athem und starb am folgenden Morgen um 8 Uhr. Der Leichnam wurde gerichtlich untersucht, die kingel ging unter der Brust zwischen der 5. und 6. Rippe durch, machte eine ungleiche und zerrissene Wunde und drang durch den Rücken, etwas unten, wieder heraus. Beim Oeffnen der Brust kam ein läutiger Sack, durch Luft ausgedehnt, zum Vorrchein, der aus dem anhängenden Netze bald als das grosse Ende des Magens erkannt warde.

Deutsche Zeitschrift $f$. Chirurgie. I, Bd. 


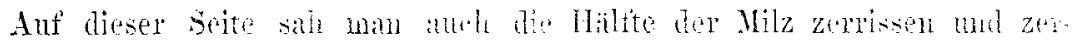

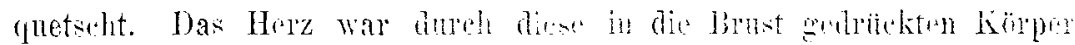

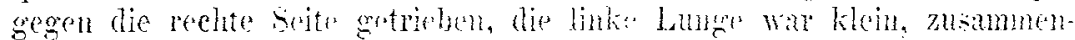

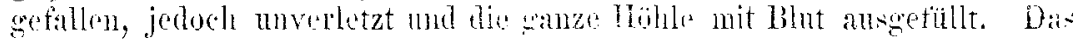
Twerehtoll zeigte in seinem solnigen thelle einen Riss $3-\frac{1}{4}$ Danums breit. Wie li., 7., b. mal 4. Rippe waren gebochen. Wegen der grosstia

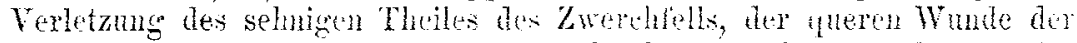
Milz und mehrerer linpenbriche wurke diese Verlotzung fïr absolu: letal crkïirt.

22) Ein Hanptmam ward durch das Ende der Cartihgo xiphoida dureh den teischigen Theil des hwepchtells geschossen, dass die Kugel

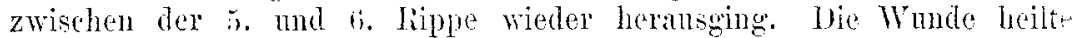
änsserlicd zu; gegen Abend und in der Nacht stellen sich hatuls: heftige schmerzen in den Gedämen cin. Solcht Schmerzen rieben ihn cndlich nach dem 8 . Monate ant. Man fand bej der bection les colos: durch eine nur fingerbreite Golfinumg des Zwerchfolls in dio Brusthöle gedringen.

23) Gutlurie theilt mit, dass er ans der Krim einen interessanton Bericht über cine Schussveretzing crhalten habe, bej welcher durch eine Zwerehfellswunde von einer Minié-Kugel der grössere Theil des Magens und des Duodenums in die Brusthöhle ausgetreten waren.

24) Fin Mensch ron 16 Jahren von starker Constitution fiel eines Morgens mnter den Schntt einer durch Sturn eingestiuzten Miner. Er wurde in ein Spital geblacht. Ein complicirter Bruch in der Mitte des rechten Beines, eine starke Contusion gegen dio Spina ossis iloi der linken Seite, eine Wunde am innern Augenwinkel dersolben Seite wareu die Verwundungen durch den Fall, die sich dem Blicke zuerst darboten. Sie wurden alle mit einer gewissenhaften Sorgfalt behaudelt. Fin kaltei Schweiss bedeckte das Gesicht des Verwundeten, dio Wangen waren mit einer blassrothen Farbe iberzogen, die obern Extremitäten waren kalt nud eine bedentende Dyspnoë vorhanden. Man richtete daher die Aufmerksamkeit melur anf die Brust, die Bedeckungen dieses Theiles zeigten aber keine Spur irgend einer Verletzung. Jede Seite wrde nit Sorsfalt untersucht, nirgends wurde eine widernaturliche Beweglichkeit oder Ver'tickung dor Theile bemerkt. Der Banch war weder schuerzhatt noch gespant. In der Blasengegend war nichts weiter zu sehen, als eine Contusion und eine leichte Excoriation gegen die Spina ussis ilei. Lebrigens überzengte man sich, dass kein Bluch in dieser Gegend war. Die Dyspnoë vermehrte sich, Gesicht und Extremitäten blicben in dem oben beschriebenen Zustande, der Puls war klein, aussetzend, unregelmässig. Einem Erguss in die Brusthöhle, den man im Verdacht hatte, schrieb man diese Zufinlle zu. Ls wurde ein Infus von Arnicablumen und eine Aderlässe verordnet. Diese Mittel waren jedoch vergebens. der Kranke erbrach das Getrank und äusserte sich mehmals: (s umwickele jhm etwas das Herz. Er starb.

Section. In der rechten Brusthöhle fand man einige Lüftel roll schwarzlichen Dlutes, aber die linke Seite der Brust war beinahe ganz vom Magen, Colon und Notze ansgefullt. Die Lunge war zurickgepresst. beinahe luftleer und auf einen ganz kleinen Raum reducirt; das Zwerch- 


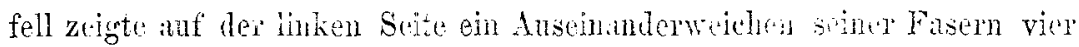
Daumen lang und einen Riss von 11,2 Danmen Breiton, der sich ron der linken Scit aus gegen die rechte erstreckte. Ant dor nämlichen Seite war, nachlem man das Colon nud den Jiagen in dir Bauchhöhle zurückgezogen hatte, ein Brach der üritten wahren Rippe siclitbar. Man untersuchte mud fand, dass die 4., 5. mil 6. Rippe gegen 3 bammen vom Ursprung der Knorpel weggebrochen waren, aber es fand durchans keine Verrückung der Theile statt. Im Banche zeigte sich nichts Frhebliches.

25) Ein 27jahlriger Mann fiel bei einer Reise von Plymouth nach London beim Aufsteigen aut den z̈ussem Sitz des Postwagens Morgens 3 Lhir mit grosser Gewalt anf den Boden zuriek. Er glanbte beim Aufstehen sich unverletzt und klagte anch nichts. Wrst am Abend des folgenden Tages, wo er in London ankam, tühite er sich sehr krank mo musste in das Spital gebracht werden. Er empfand heftige Schmerzen im linken Hypochondrium, Ekel und Bangigkeiten anf der Brrst. Der Puls war regelmässig. Es wurden 16 Unzen Bhut ans der Armvene gelassen. Am folgenden Morgen hatten die Schmerzen auf der Brust den höehsten Grad erreicht, ebenso die Beschwerden im Athmen. Es wurde viel Blut erbrochen; der Puls hatte 120 Schläge in einer Minute, war zitternd und unregelmässig; das Gesicht selrr blass, die Extremitäten kalt und die Wärme der Obcrfläche vermindert. Er starb Nacbts 11 Uhr. Section. Der Margen war entzündet, die übrigen Baucheingeweide schienen gesund. In die linke Brusthöhle waren 3 Maass (mensures) und 3 Unzen Blut ergossen, im Zwerchfell befand sich ein Theil des Magens, der durch eine Spalte desselben in die Brust reichte und mit halbgeronnenem Biute angefüllt war. Die Spalte, die sich auf der linken Seite des Zwerchmnskcls befand, hatte die Lünge eines Daumens und hatte den eingetretenen Theil des Magens fest zusammengeschnürt. Durch ein kleines Loch war das Blut, das in den Magen ergussen war, in die Brnstlü̈lìe herüber geflossens. Der Theil des Magens, der noch in der Bauchhöhle war, enthielt weder Blut, noch einen andern Stoft.

26) Der Kranke des hier erzählten Falles war ein Schieferdecker, welcher bei sehr erlitztem Körper eine grosse Menge ron mit Schwefelsäure versetzten Wasser trank. Gleich nachher ward er von den heftigsten Schmerzen in der nntern Gegend des Brustbeins befallen, die sich uiber die ganze linke Seite der Brust ansdehnten. Alles, was er genoss, ward sofort wieder ansgebrochen; der Puls war klein, fest und beschleunigt; der Athem beengt, das Gexicht bleich und ängstlich. In der Magengegend hatte er keine Schmerzen; der Unterleib sthien mehr nach dem Riickgrate gezogen. Man lielt das Uebel für eine krampfhafte Affection des Magens und diesem nach ward verfahren. Das Uebel besserte sich aber un nichts, obwohl der Kranke eine Stuhlentleerung gehabt hatte. Am Mittag des folgenden Tages liess der Schmerz in der Brust nach, dagegen entstand ein heftiger Schmerz in der Regio lumbalis der linken Seite, der sich über den ganzen Unterleib weg erstreckte. Der Unterleib war bei Berihlurugg schmerzhaft. Blutentziehungen, Blasenpflaster, Klystiere u. s. w. Wurden num in Anwendung gezogen, doch ohne Erfolg, dem der Kranke starb gegen Abend. -- Etwa ein Jahr 


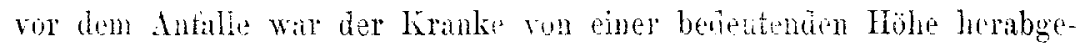
stürt und hatte oine heftigo Bristverdatzmg alitten. Ein eigenticher Ripponbruth war nicht erfolgt, os entstanden jedoch heftige schuerzen in oder ubbe der liegio eprgatrisa, denen Symptome von Entzundung machfolgten, wholb er mehere Wochen bettligerig war. Die Folgen des Sturzes waren nie ganz beseitiot worden, denn zum ötern war der Kranke ron Schmerzen in der linken Seite und brsonders in der linken Schulter und Neigung zum Erbrechen befallon worden. Fine volle Mahlzoit vermelite diese Symptome; sänerliche Speisen komnte rer nie gut vertragen. Doch ward er durch dieses Iebelsein niemals von der Arbeit abgehaltin.

Die Untorsuchung des Leichnams ergab Folgendes: Der Banch fuhlte sich hart an, war aber nicht ausgedehnt oder gespannt. Die linke Brustseite war voller als dic rechte. Alle Contenta des linken Seite der Brust wurden bei Eröffinung der Brust- und Bauchhöhle hinter dem Nagen und Arcus transversus coli und dem Netze gefunden, so dass die Fingeweide beider Höhlen eine Masse anszumachen schienen. Der Magen war ungeherter ausoedehnt und konnte beinahe eino Gallone von Flüssigkeiten halten. Derselbe füllte die ganze linke Seite der Brusthöhle ans, die Lunge dieser Seite war sehr zusammengedrückt. Aensserlich hatte der Magen eine purpurrothe Farbe. Die innere Haut desselben war schwarz von Farbe und liess sich mit dex Spitze des Finger's leicht ablösen. Das Colon war leer und ausammengezogen, von einer hellyothen Farbe, welche anch das Netz theilte. Die Theile waren durch eine ansehnliche in sehnigen Mittelpunkte des Zwerchfells sich befindende Oeffnung, dic, nach ihrem nnregelmässigen Bau und ihrer Widelnatürlichkeit überhaupt zu schliessen, durch eine frühere, bedeutende Verletzing entstanden sein musste, in die Brusthöhle gedrungen.

27) Andr. Bonn beschreibt einen an Fieber gestorbenen Mann, welcher seit 2 Jahren gehinkt und anf der rechten Seite einen Inguinalbruch gehabt hatte. Man fand bei ihm einen Knochenbruch des Halses des Schenkelbeines, ebenso waren fist alle Rippen der rechten Seite gebrochen gewesen, einige sogar zweimal, aber wieder znsammengeheilt. Der Zworchmuskel zeigte im rechten Theile seines Fleisches ein längliches, querliegendes Loch, welches einen sehmigen, glatten Rand hatte, an dem Brustfell und Bauchfell zusammengeschmolzen schienen. Das Stück des Dickdarmes, welches den Magen und die Leber zu berühren pflegt, war mit fast dem ganzen Netze hinter der Gallenblase umgebogen und durch dieses Loch in die Brusthöhle vorgefallen, wodurch ein Bruch ohne sack vorgestellt wurde, welcher innerhalb der Brusthöhle durch die Anhängsel deś Colons und durch's ausgeartete Netz, die mit Fett angefüllt waren, dieses Loch des Zwerchfells so versehloss, dass die viele in dieser Höhle befindliche und die rechte Lunge zusammendrückende Flüssigkeit nicht in die Bauchhöhle gelangen konnte. Das Brust- und Bauchfell zeigten hier herum Spuren von Entzündnng.

29) J. M., ein Zimmermam, 39 Jahre alt, fiel vom Thurme des Invalidenhanses, zuerst auf mehrere Gerüste und dann auf einen Schutthaufen. Lange Zeit blieb seine Genesung ungewiss, jedoch konnte er nach Verlauf von 5-6 Monaten seine gewöhnlichen Arbeiten wieder 
verrichten, indess klagte er noch immer über beschwerliches Athmen und einen trockenen, ofterm Hnsten, zu welehem sieh in der Folge noch ein Sohmerz in der linken Seite der Brust und fist numterbrochene Uebelkeiten gesellten. Diese Zufaille blicben sich 15 Jahre hindurch gleich, nach welcher Zeit Patient aufs neue von eimem 20 Fuss hohen Geriiste und zwar anf die linke Seit der Brust fiel. Die $T$ unteren Rippen waren gebrochen, eine nicht sehr betrühtiche Geschwulst nahm diese ganze Seite der Brust ein, am meisten spürte man sie nach linten, an welcher Stelle der Kranke zugleich iiber sehr hoftige Schmerzen klagte; er war dabei sehr beklemmt auf der Brust, unruhig und in heftiger Bewegung, die Angen waren starr, ein ununterbrochenes Blutspucken erfolgte zuweilen; das gonossene Getränk gab er sogleich durch Erbrechen von sich, das Athmenholen war kurz und sehr beschwerlich; der sehr erhobene Puls schlng schnell und ein heftiger Durst war vorhanden. Aus diesen Symptomen, die man gleich anfangs bemerken konnte, liess sich, ausser einer Verletzung der Brust, zugleich auf eine heftige Contusion des Magens schliessen. Gegen den 3. Tag hatten die Symptome etwas nachgelassen. In der 4. Nacht aber fiel er aus dem Bette, woranf die beschriebenen Symptome nicht nur mit der vorigen Heftigkeit sich wieder einstellten, sondern auch der Patient in einem Anfalle von Schlafsucht nach 15 Stunden starb.

Section. In aer Brusthöhle fand man nur etwas ausgetretenes Blut an der linken Seite. Der Magen und Bogen des Colons nahmen fast die ganze linke Seite derselben ein. Das Herz fand sich nach der rechten Seite hingedrängt, die Lunge war sehr eingefallen und ganz klein, sonst aber nicht weiter verändert. Die Bancheingeweide waren durch eine aittere Oefinung, die sich gegen den sehnigen Mittelpunkt des Zwerchfells hin befand, in die Brust eingedrungen. Die eirunde Oeffinung hatte im grössten Durchmesser dritthalb Zoll, die Ränder zeigten sich abgermdet, 2-4 Linien dick nud das bauchfell gegen die Brust zu mit selbiger verwachsen; auch hing đie Milz mit einem dieser Pänder gegen die Bauchseite zu fest zusammen. Nach der linken Seite etwas höher als diese Oeffnung fand man am Zwerchfell eine frische, etwa 3 Zoll lange Zerreissung, wodurch es von den Rippen getrennt war; durch die entstandene Oeffuung war noch ein Theil des Colons in die Brnsthöhle gedrungen. Von der 4. Rippe an waren alle bis zur untersten in ihrem Winkel gebrochen, an der 7 . bemerkte man sogar 2 Brüche und an der 6. mehrere Splitter, doch war keinc dieser Rippen aus ihrer gewöhnlichen Lage gewichen.

29) Dr. Preuss beobachtete folgenden Zwerchfellbruch. Grenadiel" F. Sch., 72 Jahre alt, ledigen Standes, litt seit einigen Jahren her an öftern Anfällen von Schwindel, Aufstossen, Ekel, Magenkrampf, Cardialgie und zuweilen an wirklichem Erbrechen. Bei diesen so bewandten Umständen war sich der Mann gewöhnlich selbst sein Arzt, er hielt sich ruhig, beobachtete Diät und war bald wieder von seinem Leiden auf kuirzere oder längere Zeit befreit. Den 17. April 1798 wurde er in das Spital gebracht. Er klagte über kurze Anfälle von Schwindel, Abgeschlagenheit des ganzen Kürpers und Drücken in der Magengegend, er erbrach sich, so of er etwas zul sich genommen hatte, sein Appetit 


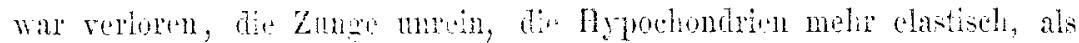

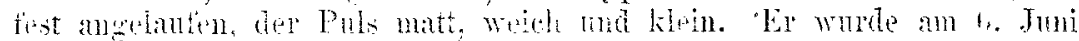

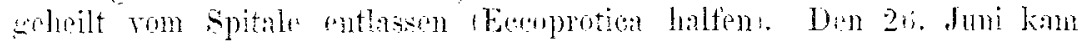

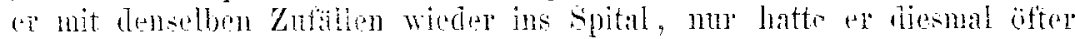
als zuvor Antialle von sohwindel; Laxantien halten wider. Don lo. Uctober wuate er abermals strek von Erbreten angegritien, am 1 l. Uctober

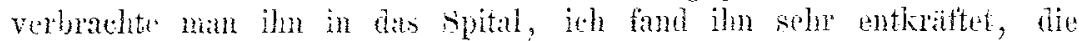
Stimme matt und heison, die Zunge sabureos, nit einer gelben hruste iiberzogen; rer klagte ubur Bremien anf der Brtst nud Druck im Magen, die Hypochondrion waren Intschwibtig anfortrieben - er erbrach, was

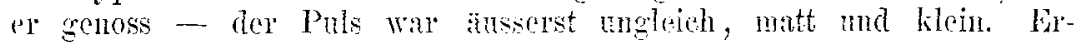
weichende Klysticre und Sancrtug auf dif Fussohlen gelegt rermochten endlich so viel, dass man dem hianken mach und nach otwas von einer eccoprotisclen Mixtm and suppe beibringen konntc. Dir IIilfte des Genossunch erbrach er inmer und er starb, nachdem die kriste ilm schnell verliessen, den 12. Octoler Abends mach 9 Lhr. Bè der Section fand ich cine grosse Oefnung im Zwerelnfell, mehr rechterseits an dessen

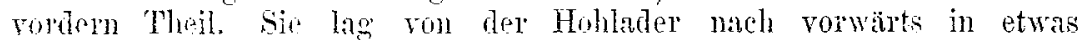
scheier Linir gogen 2 Zoll entfernt, ihre Fignu war oral, ilr längerer Durchmesser ging ron einer Soite zur andern, und betrug 2 starke Zoll; der kiurzere hingegin ron rorne nach hinten hatte einige Linien weniger als der grösere. Die Rönder der Uefnung waren sehmig abgerundet, etwas autgeworten und wulstig gegen die Fläche des Zwerehfells zu anzufühlen; das das Zwerchfell iberziehende Brust- und biuchfell sah man dentlich an einigen Stollen des Randes der Oefinung, nach der Brusthohle gerichtet, fransig und wie grwaltsam zerrissen unter den dureh die Oefinung laufenden Gedärmen herliegen. Der Magen war widernaturlich gross und ron den Arzmeien u. s. w. ansgedehnt; er lag grösstentheils im Hypochondrim, hintex ihm gegen den Rïekgrat lag die Leber, die Milz und die Banchspeicheldrüse. Die Leber war kleiner als im natülichen Zustande, ihne Structur aber natürlich beschaffen, ihn rechter Lappen war wit der Fena cava inferior und diese dagegen mit dem Duodenum rerwachsen; das Ligamentum suspensorium heftete die Leber an einem Theile des Randes der Oefinungen. An eben dieser Stelle befand sich ein besonderer Fortsatz ron der Substanz der Leber gebildet, in der Grösse eines Zolls, der ebenfalls mit dem Rande der Oeftinung fest rerwachsen und nach der Brusthöle zn gerichtet war. Anch das Duodenum wich von seiner normalen Lage ab und das Jejunum, Ileum und ein grosser Theil ron ihren Gekrösen befanden sich in der Brusthöhle gelagert. Das Ende des Ileum kam ron der Brusthöhle dureh das Loch in die Banchhöhle.

Das Coecum war zwar in der Regio iliaca dextra, aber fest an das Banchfell angewachsen; von da ging das Colon ascendens nach dem rechten Hypochondrium, hinter der Leber und der obern Gekrösschlagader rorbei und durch das Loch rechterseits in die Brusthöhle, machte in derselben einige Windungen und ging hierauf wieder durch das Loch aus der Brusthöhle linkerseits in die Banchhöhle heraus. Es ging also das Fnde des Dnodenum in die Brust, das Ende des Ileum heraus in den Banch, der aufsteigende Theil des Colon in die Brust hinein, der ab- 
steigente Theil desselben wieder zuriek hrans nebst dem Gokröse und fler obren Gekrösmehligader. Nur die Gedirme in der Brost waren rntzindet und zwar in holem Grade. Langen nnd Herz waren grestnd und :ehörig gelagert, die rechte Lunge anfwairts sedrückt, aber die Lorta sammt den von ihr entstehonden grössem schlactadern der Brust und des Banchs fand ich widernatiirlich erweitert. Besonders merkwürdig ist es. dass die durch das Loch gedrungenen Gedirme alle an der Stelle ihres Durehtrittes widematiurlieh soh verengert wimen, und ebeno merkwirdig ist as, dass der Kranke nie uiber Beklommenheit seiner Brtst, noch über irgend einen Fehler seiner Respiration klagte. Wie und anf welche Art die Oefhumg extstmden ind wie lange sie zugegen gowesen sein mag, kann ich, führ't Dr. I'renss fort, nicht gerade erörtern und vermeide alle scheinbaren Gründe zu untersuchen und anzugeben, soviel aber ist gewiss, dass der Hann, nach dem Zeugniss eines Offiziers nnd einiger alten Lameraden, vor etlichen 20 Jahren von ungefülr über die Fenster rom zweiten Stock der Kaserne auf das steinptlaster sehr gefährlich herabgefallen, aber ohne irgend cinen hinterlassenen Fehler damals geheilt worden sei. Man könnte daher mit vielem Grunde schliessen, dass durch die damalige grosse Erschitterung bei dem Falle und durch das Andringen der zunächst an das Zwerchfell angelegenen Theile die Stelle vorzïglich und besonders geschwächt, und sofort durch jede gewaltsame Erschütterung, z. B. durch Husten, Niessen u. s. f. die geschwächte Stelle durchbrochen, den Gedärmen nach und nach der Eintritt in die Brusthöhle gestattet und auf solche Art der Bruch gebildet worden sein müsse. Dies lässt nicht allein die besondere Verwachsung, sontern anch die ganz besondere Richtung der Gedärme vermuthen.

30) Im Herbst 1S25 wurde anf die Anatomie zu Tübingen der Leichnam eines 69jahluigen Mannes gebracht. Als Dreifus an dieser Leiche die Operation des Empyems machte, kam ihm, nachdem er die Pletrra angestochen, ein Gestank aus der Brusthöhle entgegen, wie er sonst nur in der Bauchhöhlo sich entwickelt. Bei der Section fand er die Ursache dieser ihn, wie er sagt, überraschenden Erscheinung. Ein Theil des Colon, der bei genaucrer Untersuchung als Colon transversum sich zeigte, lag in der rechten Scite der Brusthöhle. Dieser Darm drang durch eine widernaturliche Oeffumg im rechten sehnigen Theile des Zwerchfells, welche eine rundliche Form und gegen $1 \frac{1 / 2}{}$ Zoll im längern Durchmesser (von vorne nach linten) hatte, ziemlich nach vorne gelagert und mit einer Nembram versehen war, nnter welcher der Darm wie nuter einem Vorhange in die Brusthühle drang; es hatte der Bau dieser Oeffinung mit dem Fornmen ovale des Herzens die grösste Aehnlichkeit. Der Darm lag in der Brnsthöhle völlig nackt, hatte die rechte Lunge bedeutend zurückgedrängt und kehrte durch dieselbe Oeffinung wieder in die Banchhöhle zuritick. Das Colon descendens stieg von der Oeffinung des Zwerchfells an schief gegen das S. romanum herab; eine Flexura colica sinistra war nicht vorhanden. Die Lunge, das Herz und die Eingeweide des Bauchs waren gestund; dies galt besonders auch ron dem in der Brust enthaltenen Darm. Pleura und Peritonaeum bildeten gleichsam eine zusammenhüngende Membran. Die weitere Lntersuchung des Leiehnams zeigte starke Verknöcherung der Arterien und an der 6. Rippe 


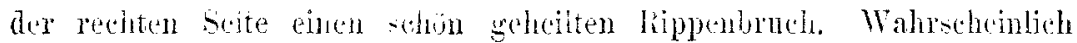

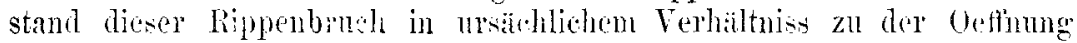
im Zwe Jehfell. Doul ist höchst merkwürdig, dass dor Mamn niemals gegen some Kameraden rtwas geklagt, nie in sumen Leben an Asthma oder Beschwerden in Athemholen ibberhanyt geliten hatte und noch im letzten Jahre seines Lebens als Zimmormann thätig war.

31) Ein Arbeitsmann erlitt bui einel Verschiittung eine Fractur der 5. rechten Rippe in ilireu Vittelstioke. Er hatte sogleich heftigo Athembeschwerden und Schmerzen in der rechten Brusthälfte empfunden. Die Pereussion wurle anf dieser Soite allmailig immer höher hinauf matt, während sie in der obern Hälfte tympanitisch war. Statt des Athemgeränsches fand man nach einiger Zeit anf dieser Seite amphorischen Widerhall und metallisches Klingen. Hiernach wurde die Diagnose anf Hydro-l'nemothorax gestellt. Der Tod erfolgte $1+$ Tage nach der Verletzung unter Erstickungserscheinmogen, ohne dass irgend cin Symptom anf ein wesenthehes Leiden der Verdaumgsorgane hätte schliessen lassen. Bei der Section fand man keinen Erguss in der Pleurahohle. Links war das Zwerchell bis z!n Hohe der fünften Rippo emporgewölbt, rechts schien auf den ersten Blick die ganze Plenrä̈̈hle durch mindestens die Hälfte des Dickdarms ausgefuillt zu sein. Nachdem man die Darmstücke, welche sich bis zum Schlisselbein erstreckten, zurickgeschoben hatte, zeigte sich die rechte Lunge bis anf das Volumen einer Fanst gegen die Wirbelsaule comprimirt, durch einige Adlüsionen an der Spitze nach oben fixirt. Im Zwerehfell fand sich ein Riss, durch welchen die Eingeweide ihren $\mathrm{Weg}$ genommen hatten, etwa $20 \mathrm{Ctm}$. lang; in der Richtung von rechts und linten nach links and vorne. Derselbe war durch die hindurchgetretenen Theile zu einer ringfömigen Oefiung ausgeweitet. Ausser dem schon erwähnten Dickdarm war auch fast der ganze rechte Leberlappen in die rechte Pleurahöhle eingedrungen. Nirgend hatten die eingedrungenen Eingeweide einen Ueberzug, anch bestanden keine Adhäsionen, weder mit der Pleura noch mit dem Zwerchfell.

32) Ein 22 jähriger Mamn, der vor 6 Jahren durch einch Lnfall seinen rechten Arm verloren hatte, bekam in Folge einer Rauferei plötzlich heftige Schmerzen in der linken Seite, worauf hochgradrigo Dyspnoë, Uebelkeiten, Erbrechen, Schlnksen und nach 40 Stunden der Tod erfolgte. Die gerichtsärztliche Untersuchung ergab äusserlich keine Verletzung; nur die linke Seite war, da der rechte Arm fehlte, etwas stärker entwickelt mal in der linken Regio iliaca war eine geringe Anftreibmng und schwäraliche Hantfarbe les waren Blutegel gesetzt worden) bemerklich. Bei der Leichenoffnung fand sich daselbst mässige Peritonitis und beträchtliche Püthung der Dünndärme. Das Herz war normal gross, die Spitze nach rechts verschoben; die rechte Innge atrophirt, kanm halb so gross als die linke, die letztere war in ihrem nuteren Theile comprimirt und verdringt durch das Colon transversum, das Netz, die Milz und den Magen, welche sämmtlich durch die abnorm erweiterte Oesophagusüfunng in die Brusthöhle eingedrungen waren. Diese Oeffnung war um 10 Ctm. grösser als gewöhnlich, war elliptisch, begann etwa 2 Ctm. von dem Rippenansatze der Zwerchfellfasern und ging nahe bis an das Centrum des $Z$ werchfells. Die linke Lunge war durch diesen 
Druck schwärzlich gran gefärbt; die Pleuren nicht entzündet. Das Zustandekommen dieser eigenthümlichen Zwerchfulshernie erklärt Waton mehr durch die lieftigen Anstrengungen, whlot der Verletzte hatte machen müssen, um sich seinen Verfolgern zu entziehen, weniger durch einen directen Druck anf den Unterleib, obgleich er hieranf die vorhandene partielle Peritonitis beziehen zu müssen glaubt. Zugleich nimmt Waton präexistivende lind zum Zwerchfellsbruch prädisponirende Erweiterung der Oesophagusöffung an. Indem der rechte Arm fehlte, so musste, wie er glaubt, die linke Thoraxhälfte stäkere Anstrengungen machen und dadurch wurden die Zwerchfellsfasern links gezert und wichen num bei einer gesteigrorten Anstrengung um so leichter auseinander.

33) Ein 20 jälriger Mam, früher immer gesund, hatte seit einem Falle anf dem Lise vor zwei Jahren sich nie recht wohl befunden 19 Stunden vor seiner Aufnahme in das Spital glitt er in seiner Wohnung ans und gab sich, um sich aufrecht zu erhalten, eine gewaltsame Drehung, worauf er sofort dio heftigsten Schmerzen cmpfand, so dass er mehrere Minuten lang kaum aufathmen konnte. Bei der Aufnahme zeigte der Kranke einen ängstlichen Gesichtsausdruck, hatte aber nur greringe Schmerzen in der linken untern Thoraxpartie. Der Pnls war 105, klein und schwach, die Hauttemperatur nicht erhöht. Die linke Thoraxhältte war bedentend stärker gewölbt als die rechte und die Intercostalmuskeln stark vorgetrieben; Athembewegungen waren fast nur in der spitze bemerkbar, während die rechte suite stark athmete. Das Herz war uach rechts verdrängt und soin Stoss im 5.--7. Intercostalraum zu füblen. Der Percussionston war links vorn abnorm voll und klingend, nur an der Spitze etwas wuiger voll, hinten 'utsclieden gedämpft, rechts iiberall normal. Dyspnoë war nicht vorhanden, trat aber sofort ein, wenn sich der Kranke anf die rechte seite legte. Bald stellte sich Erbrechen ein von nnverdauten Speiseresten, und in der Nacht wiederholte sich das Erbrechen von dickem zähen Schlcim fast alle 10 Minnten und machte die Einführung von Medicamenten oder Nalurungsmitteh fast ganz unmöglich. Einige stunden vor dem Tode erbrach der Kranke eine grosse Menge schwarzes wie halb verdantes Blut, dasselbe wiederholte sich, heftiger Durst, kalter, zäher Schweiss, Delirien stellten sich ein, der Puls ward fast ummerklich und 51 Stunden nach dem Zufalle erfolgte der Tod. Bei der Section fand sich das Herz in der angegebenen Lage auf die rechte Lunge drïckend; das Pericardinm blutig injicirt, lose verklebt, die rechte Lunge ansserordentlich blutreich, aber uiberall lufthaltig, die linke Lunge, mit Ansnahme der Ränder, völlig carnificirt und Inftleer. In der linken Plenrahöhle fanden sich etwa 6 Nösel selhwarzer, düner Flüssigkeit, mit Speiseresten vermengt und im nuterm Theile ragten durch eine grosse Oeffnung des Zwerchfells der Magen, das grosse Netz, der grössere Theil des Colon transversum und die Milz in die Brusthöhle hinein. Der Oesophagus war zurückgekrïmmt mit seiner Convexität nach unten, der Magen zusammengefallen, mit der grossen Curvatur nach oben gerichtet. Die Magenwände, besonders in dem hintern Cardiatheile sehr verdünnt, zeigten an einer stelle eine etwa groschengrosse Oefinung, der geringe Mageninhalt war ähnlich der in der linken Pleurahohle gefundenen Flüssigkeit und bestand aus halb- 


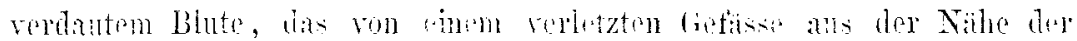

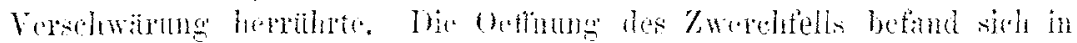

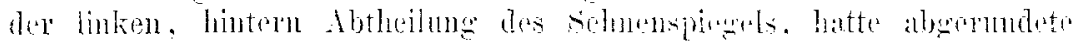

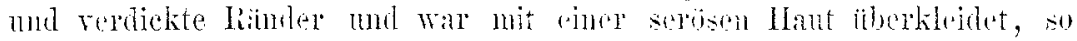

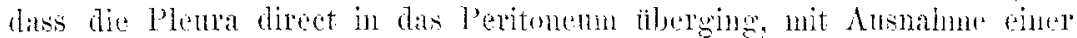

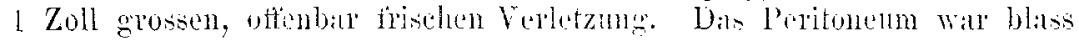

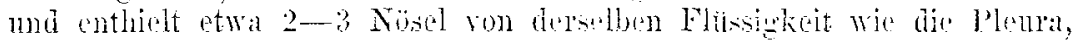

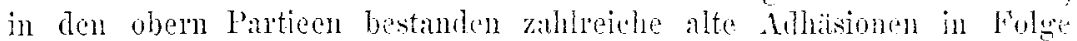
ciner alten Peritonitis. Dieser Fall, Jeist as woter, ist von besonderem

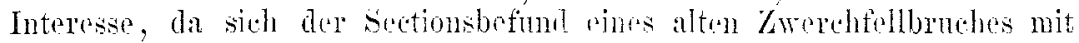
einer frischen Erwoiterung desselben fast mit Bestimmtheit anf eine liuhere trammatische Einwirkng und anf eine ('rst kürzlich erfolgte leftige Er-

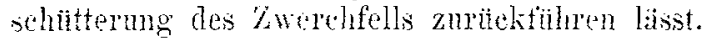

34) Culpan godentet eines Falles ron Dislocation des Magens bei einem Mame, der nach starker Ermüdung und Mageniborladung Anfalle ron Cobelkeit und Erbrechen bekommen hatte. Dabei kalte nnd klobrige Haut, schneller nnd kleiner Puls, ingstliches nul vorzerites Aussehen, Schlncksen, vergebliche Irechrerstohe, kejne Schmerzhaftigkeit des Linterleibes, keine Tympanitis. Nach wenigen stunden 'Tod. Bei der' Fröfinnng der Brist sah man eine ungewöhnlich grosse, tympanitisch aufgetricbene, blasenartige Masse, die man anfings für das abnorm ansodehnte Pericardium hielt, die sich aber dam als nach oben vor das Herz durch eine frisehe Riuptur des Diaphragma dislocirter Magen herausstellte.

35) In einem von Bochdalek mitgetheilten Falle latte der Verunglückto durch grosse Kohlenstücke, dio ihm auf den Ritcken fielen, eine Fractur des 1. nnd 5 . Lendenwinkels und des Krenzbeins erlitten und gleichzeitig war bei demselben eine Zwerehfellshernie entstanden. Der Patient war an den untern Extremitäten gelälnmt, er starb aber erst s Wochen nach dem Unfalle durch die Verletang des Ruickenmarks mit folgender Pyämie. - An den Brustorganen war umittelbar nach der Verletzung nichts Krankhates beobachtet worden, aber in der Nacht nach derselben entstanclen Athembeklemmungen mit Gefühl von Erstickmng, es trat Schleinrasseln anf und bei der Perenssion ergab die linke Seite des Thorax und Lnterleibes den Ton eines leeren, lülzernen Fasses, während diese Seite stark aufgetrieben war. Stuhlentlecrungen verminderten die Athembeschwerden und verringerten das Folumen des brustkorbes und Unterleibes. Während des Swöhentlichen Krankheitsverlaufes hatten sich die Athembeschwerden im Ganzen verringert und waren nur zeitweise bedentender geworden. Bei der Section wurde der von Gas und Flüssigkeiten ausgedehnte, grosse Magen, ein Theil des stark anfoblähten Colon transversum, die obern 2 Drittel des Diinnclarmes und die obere Spitze der Milz in der Brusthöhle gefunden. In der linksseitigen Hälfte des Rippentheiles des Zwerchfelles befand sich eine beinahe kreisrunde Oeffmung von der Grösse, dass man bequem eine mässig grosse Mamnesfaust durehfühpen konnte $13^{\prime \prime}$ in querer und $3^{1} 4^{\prime \prime}$ in gerader Richtung). Der Umfangrand des Loches war dick, wulstig und abgerundet, nur der bereits in den sehnigen Abschnitt greifende, kleinste Theil sehr dünn, nueben, gefranst, wie frisch eingerissen und die Plenra

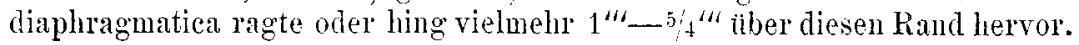




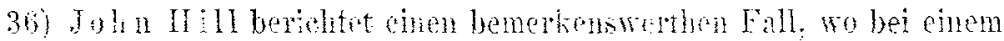
verschiitteten Wame, aer noch 22 Tag. nach de? Verletzing geleht latte,

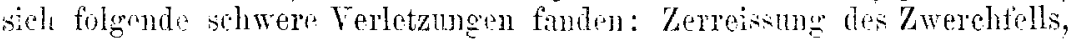
Hämothurax dexter mit compression der Lungen, die Leber lag mit dem rechten Lappen im Thoraxrantin und war rollstimdig ungedreht, so dass ihre Oberfliiele ganz nach rorne gewandt war, ailsserden zeigte sie einen tiefen Riss, ebenso war die rechte Niere zerrissen.

37) Jin Mann wurde nach selur reidhichem Gemuss von Brassiea eapitata, die in Salz eingemacht war, und von Erbsen von so heftigem Brechen, Bangigkeit, einem so brennenden, kolikartigen Schmerz uni so heftiger Verstopfing befallen. dass er nach wenigen Stunden den Geist aufgab. Das dicke Ende des Magens mit dem Netze fand man durch eine weite Oefinung in selmigen Theile des Zwerchfells in die Brnst gedrungen

35) St. Andrä erzithlt von einem Menschen, der viel Wein und Bier getrunken hatte und den Tag darauf heftiges Erbrechen und Kolikschmerzen bekam. Alle Hülfe wurde vergebens aingewandt. Der Ĺrunke starb bald. Be: der Section fand sich ein Theil des Colon und Netzes mit dem Pankreas neben dem Nerrus. sympathicus in die Brust eingedrungen und brandig. Das Jejunum und Ilemm war rom Bier moeheuer ansgedehnt.

39) Schober entdeckte bei einem Mamne, der lange an Krebs der Leber litt und nach einer nngewohnten Schifffahlit unter sehr häufigen Erbrechen einer schwarzen, stinkenden Materie and heftigem Schlnchzen starb, Magen, Netz, Duodentum, Jejunum und einen Theil des Ileum in der Brust. Das Zwerehfell war unverletzt, nur das Foramen oesophageum war sehr erweitert und erschlafft.

40) Ein sojähriger Mann, dem Trunke sehr ergeben, wurde von verschiedenen, rhenmatischen Schmerzen, starkem Erbrechen und erschwertem Athmen geplagt, was bald hertiger wurde und dem Kranken das Leben raubte. Die linke Lunge schwamm in einer schmutzigen Flüssigkeit, die sehr verschieden war von den Feuchtigkeiten, die man sonst in der Brust trifft. Nachdem diese Flïssigkeit entfernt war, zeigte sich das $Z$ werchfell durchbohrt und zerrissen; durch diese Oeftnung drängten sich Lappen eines häntigen f:ulligen Körpers, der nichts Anderes war als ein Theil des Magens, welcher gleich einem Bruch in die Oeffinung des Zwerchfells eingeklemmt war. Im Banch kam nun der übrige Theil des Magens entzündet und brandig zum Vorschein. Der Theil des Zwerchfells, der dem Magen am nächsten liegt, und der ihm am meisten genïherte Lappen der Leber war ebenfalls entzïndet und brandig.

41) In dem Leichnam einer Fran, die mehrere Jahre an heftigem Grimmen und Erbrechen laboriste, und anch an letzterem starb, fand sich im linken, musculösen Theile des Zwerchfells ein zwei Daumen breites rundes Loch, dessen Pand mit Falten und kreisförmigen Klappen, beinahe wie der Pylorus, rersehen war. Diese Oeffinung durchbohrte das Zwerchfell und bildete mit dem Mediastinum und dem Zwerchfell einen häutigen Sack, auf der linken Seite aber gleichsam eine Duplicatur des Zwerchfells. In der Brusthöhle lag der grüsste Theil des Magens mit dem Netze.

42) Ein altes Franenzimmer wurde vor 15 Jahren nach einer Mahl- 


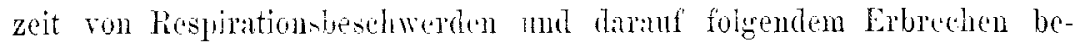
fallen. Sie mutrelag einem Entzündungsiober. Man fand keinen Magen im Batleh, die nngeheler crosse laber fïllte das ganze Epigastrium aus; beim Ueffinen der brust lag der Magen oberhalb des Zwerchelles.

Es würde mich zu weit führes, jeden der angefülnten von fremulen Beobachtern mitgetheilten Fälle anch nur cingermassen eines Kritik zu unterziches, ich glanbe mich mit der Antühlinng begnügen zu hömen und reihe jetzt die beiden vun mir beobachteten Fille an.

43) Im Monate Februar $1570 \mathrm{kam}$ anf der Abtheilung des Herm Geheimrath von Gietl ein Fall von Incarceration einer durch ein Trauma entstandenen Zwordhfollshenie zur Beohachtung. Die Zwerehfellshernie als solche war bedingt durch eine im Soptember 156 s erfolgte Verletzumg, die Incarceration trat, wie schon erwähnt, erst im Februar 1870 ein. Beide botreffende Krankheitsgeschichten werde ich in aller Kürze anführen. Nach erhaltener Wunde kam Patientin, ein 15 jähriges Mädchen, ant die chirurgische Abtheinng des Herm Professor von $\mathrm{N}$ us s ban m. Da ich zu jener Zeit schon diese Klinik besnchte und in Winter 1570 bei Herrn Geheimrath von Gietl practicirte, so hatto ich Gelegenheit den Fall in seinem Ursprunge und Verlaufe zu beobachten. Bei ihrer Aufuahme gab Patientin an, am Abend des vorigen Tages einen Stich von rückwärts in die Brust erhalten und dabei viel Blut verloren zu haben. Ein herbeigeholter Arzt hatte die Wunle durch die blutige Naht geschlossen und die Blutung durch Compression vermittelst eines Charpieballens und Heftpflasterstreifen gestillt. Bei der Inspection zejgte sich am Rücken links von der Wirbclsäule etwas nach unten und innen vom nutern Winkel des Schnlterblattes in achten Intercostalraum eine scharfrandige, horizontal verlaufende $W$ unde von 1 Zoll Länge mit 3 Suturen vereinigt. Am äussern Wundwinkel sickerte etwas Blut aus. Die Umgebung der Wunde zeigte Emplyssem des Zellgewebes in der Ausdehnung einer Vola manus. Die Percussion ergab keine Dampfung, bei der Anscultation war uberall ganz normales, vesiculäres Athmen zu hören. Auch wurde versichert, dass kein Blut ansgehustet worden war. An der linken Schulter, sowie in der Umgebung der Wunde klagte Patientin boi leiser Berührnng lebhaft Schmerz. Der Interleib zeigte sich gegen Druck niclit im Geringsten empfindlich. Puls machte 100 Schläge in der Minute; Temperaturerhöhmng war nicht wesentlich. Die Suturen liess man in der Wunde liegen und legrte dazwischen noch zur bessern Vereinigung der Wundränder Heftptlasterstreifen. Sonst wirde antiplilogistisch verfahren und zur Linderung der Schmerzen Morphium subcutan injicirt.

Am Abende des 2. Tages stellten sich Athembeschwerden cin, doch wichen sie rasch wieder nach Anwendung Priessnitzischer Umschläge und Darreichung Hoffmann'scher Tropfen. Am 4. Tage wurden die Nähte entfernt, es zeigte sich schöne Eiterung und üppige Grannlation. Hingegen stellte sich Husten ein und wurden eitrige Sputa ausgeworfen, auch liess sich bei der Auscultation von der Stichwunde gegen die Wirbelsäule zu pleuritisches Reibungsgeräusch vernehmen. Die Pleuritis nahm einen sehr raschen und günstigen Verlauf; die Grannlationen wucherten sehr schön, so dass am 16. Tage der Krankheit die Wunde schon fast vollständig wieder vernarbt war, und Patientin auf ibq Verlangen aus 
dem Spitale entlassen wurde. Dit physikalische Lntersuchung ergab zu dieser Zeit am linken untorn Lungenlappen rerschärftes Athmen, Durchschlagen der Stimme war' deutlich zu vernehmen. - Schon bei der ersten Besichtigung der Wunde tauchte die Vermuthnuy auf, dass man es mit einer penetrirenden Brustwunde zu thun labe, doeh liess sieh eine genaue Diagnose nicht stellen, zumal da die Untersuchung mit der Sonde, welche allein gewüuschten Aufschluss geben könnte, bei Brust- oder Cnterleibs-Wunden, wenn es zweifelhaft ist, ob sio penetriren oder nicht, nach den jetzigen Grundsätzen der Chirugie als Kunstfehler za bezeichnen ist.

Am 20. Februar 1870, also 18 Monate nach erlittener Verletzmo: kam Patientin - inzwischen verheirathet - wieder in das spital und suchte wegen heftiger im ganzen Cnterleibe verbreiteter Schmerzen ärztliche Hülfe auf. Als Ursache ihrer Erkrankung beschuldigte sie Verdruss und Stuhlverstopfung. Herz und Lunge zeigten sich bei der Untersuchung frei von irgend welcher Affection. Abdomen war gespannt und bei Druck oberhalb der Symphyse empfindlich. Menses wurden eben elwartet. Bei absoluter Diät ward ein warmes Getränk verordnet und ein Klystier applicirt. Leber Tags nalmen die Schmerzen zu, der Leib wurde anfgetrieben und sehr gespannt. Im Lanfe des Tages wurden acht Blutegel an das Abdomen gesetzt, im Verlaufe des Abends und der Nacht wurden drei halbgränige Opiumpulver verabreicht. Schon am 2. Krankheitstage stellte sich unter Fortdauer der Schmerzen Erbrechen grün gefärbter, flüssiger Massen ein. Es ward mit Darreichung ron Opium fortgefaliren und Kälte auf das Abdomen durch Auflegen von Eisblasen angewandt. Am 3. Tage zeigte sich namentlich die Coecalgegend stark hervorgetrieben, anch liess sich daselbst hie und da ein leichtes Schwappen fühlen. Schmerzhaftigkeit und Erbrechen danerte an. An die Coecalgegend wurden zehn Blutegel gesetzt. Am S. Tage ging ein fester Stuhl mit Blahungen ab. Am 10. Tage trat Collaps ein, während der Leib sich immer mehr und mehr auftrieb. Puls ward inmer kleiner, Leibschmerzen melirten sich trotz Fortsetzung des Opiungebrauches. Collaps ward durch Darreichung von schwarzem Kaffee mehrmals vorübergehend beseitigt. Am 15. Tage wurden die Leibschmerzen selur heftig. Auf ein Kaltwasserklystier erfolgte Stuhlgang, jedoch gingen nur einzelne Kothklümpchen weg. Eine Injection von 0,015 Gramm Morphium erzielte während der Nacht ziemliche Ruhe und subjectives Wohlbefinden. Im Laufe des 16. Tages stellte sich abermals Collaps ein, die Prominenzen wurden rasch ganz kühl; der Puls flatternd; der Leib blieb wie am rorhergehenden Tage stark anfgetrieben. Drei Kaltwasserklystiere wurden applicirt. Nachmittags $4 \mathrm{Chr}$ trat exquisites Kothbrechen ein. Die sich Abends einstellenden furchtbaren Schmerzen wurden durch subcutane Injection von Morphium beseitigt. Wührend"der Nacht collabirte Patientin vollkommen und starb am frühen Morgen des 17. Krankheitstages. - bei ihrem Eintritte schon zeigte Patientin Symptome, welehe zur Anmahme einer Peritonitis bestimmten, gegen welche denn auch sofort mit den indicirten Mitteln angekämpft wurde. Eine sofort vorgenommene genaue Untersuchung der Bruchpforten ergab nichts Positives. Schon in den ersten Tagen wurde mit aller Bestimmt- 


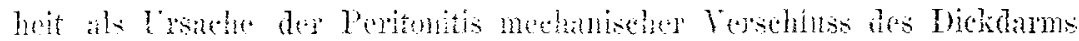

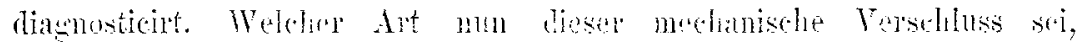
konnte in diestu, wo woll in den mosten Filloil nicht mit Bestimmtheit elnist werden.

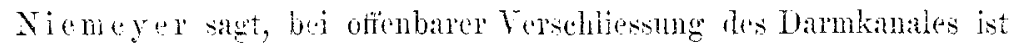
es fast in keinem Falle wäluend des Lebens mit sicherheit zu arement

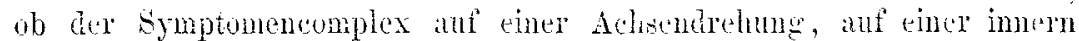
Einklemmung, auf einer Intususcoption oder anf einer Verschliessmer des Dames durch harte Faeces oder steinge Cuncremente berult.

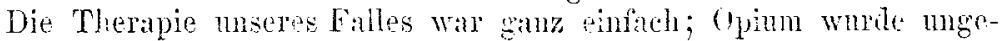
schent in srosser Qunntitat gereicht, theils mo ren Darm ruliog zu halten,

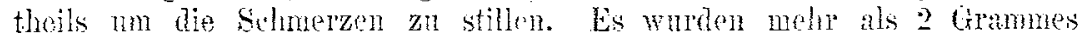
imnerhatb $1+$ Tagen in 76 bosen als Pulver verbrancht, ohne dass anch nur im Geringsten hitoxicationserscheinumgen aufgetroten wären. Ansserdem wurden noch nebst der entsprechenden Diat fortwähend Eisstickch sereicht. Schwarzer Kaflee crwies sich bei drohenden Colips mehrmals sehr wirksam. Aeusserlich wurde die Kälte durch mehrfacho Eisblasen anl den Unterleib angewandt. Kaltwasserklystiere wurden zur Beschränkung der Ausdehnung der Damngase und zur Unterstützmg dex Antiphlogose gegeben. Die gleich in den ersten Tagen gemachten örtichen Bhutentzielnugen warden theils zum Zwecke der Schmerzstilung, theils als Antiphlogisticm verordnet. - Die am 7. Mitrz rolgenommene section ergab tolgente dem Scotions-Jomnal des Horra Professor Bahl entnommene Daten. Der Körper ist klein, schlank, ziemlich schwächlich, Fettpolster schwach entwickelt, ebenso zejgt sich die Musculatur schwach entwickelt nud dunkel gefarbt. Die Hautfarbe blass, weiss. Abdomen sehr stark aufgetrieben, namentlich in der Mittellinie vorgedrängt. Im achten linken Zwischenrippenraume findet sich eine $1^{\prime \prime}$ lange, wenig sichtbare Narbe, am obern Rande ter 9. Rippe in der Gegend des Angulus costae findet sich eine kleine nach imnen stehende Exostose, etwa $t^{\prime \prime}$ lang, sehr spitzig. Rechte Lunge ist normal. Die linke Lmnge ist etwas im Volumen verkleinert, das Gewebo selbst normal; die Pleura der ganzen linken Lunge, namentlich aber des Unterlappens ist an der Anssentidche mit der Rippenpleura vorwachen. Hit der Basis der linken Lunge fanden sich stringe fest verwachsen, die sich bei naherer Bsichtigung als Netzpartieen darstellen. Das Zwerchfell zeigt an einer, der Mitte der linken Lungenbasis entsprechenden stello (boi nuassiger Wülbung gegen die Brusthöhle) eine etwa halbguldengrosse Oattinung; die Ränder derselben sind vollkommen vernarbt und geglättet. Durch diese Oeffnung zeigt sich eine Partie Netz und ein etwa $6^{\prime \prime}$ Ianges Stiick rom Colon transversum schlingenartig ans der Banchlöhle in die Brusthöhle hineingeschoben. Das Herz ist in seiner Lage kaum verdrängt, in jeder Beziehung nomal. Beim Einschneiden in das Abdomen zischt Luft aus, kothiger Geruch ist wannelunbar. Die Gedaine sind aufgetrieben. In der Baudhöhle findet sich mässig viel füssiges, hothig riechendes und dureh Koth getrübtes, gulbgefürbtes Exsudat. Auf den Darmschlingen liegen spärliche Flocken eines ebenfalls kothig gefirbten Faserstoff-Exsudates. Das Colon transversum zeigt sich mit dem Netze vor und links von dem Magen durch die Zwerchfellsöffnung in die linke 


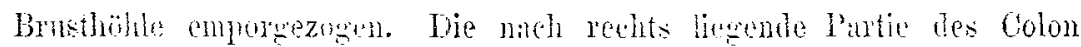
transversum, sowio lats Colon adscendens und das Coecum sind dureh eine beträchtliche Mange dickflüssion geiben hothes ausgedehnt, die

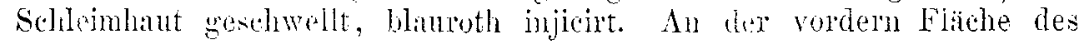
Coucim zeigt sich an der Schleimlant ein kronenthaherorosser substanzverlast, von welchem ans zwei atwa federkielgrosse Purforationsstellen durel Huscularis und Serosa froi in die Bawhinhe wanden. Am Peritonealiburug der bezeichneten Flïche des Coecum zejgen sich die beiden Perforationsitellen solnarz nnandet, bei der guringsten Bewegung des Cooctum entleot sich Koth. Milz ist klem, die Kapsel schwarz-blau gefarbt. Die Loberobertäche ist blatu-schwarz gefabbt und erstreckt sich diese Farbung $2^{\prime \prime}$ ticf in das sonst normale l'arenchym der Leber. Nieren sind in missigen Grade cyanotisch. Spuren der yon Patientin angegebenen früheren Peritonitis fanden sich nicht. Dic am Coceum betindichen Perforationsstellen sind durch stercoralen Drackbrand, in Folge des imnen drückenden angestauten Kothes und der von den Seiten her diückenden stark aufgeblähten Darmpartieen entstanden. Die Perforation and durch sie der Kothaustritt sind also directe Folgen der Incarecration der IIenie. Die blauschwarze Färbung der Leberoberfläche ist durch das frei in der Banchliöhle befindiche Darmgas erzengt. Dio Lage der Narbe im 8. Intercostalramme, sowie die Exustose am obern Rande der 9. Rippe lassen mit der grössten Bestimmtheit erkenuen, dass der Stich schräg ron oben nach abwärts cindrang. Wie nun fragliche Verletzung ohme Betheiligung der Lunge zu stande kommen kounte, libst sich bei nahorer Würdigung der Beziehmngen des Zwerchfells zu den Respirationsbewegnngen nud der Versiliebungen aer Lunge bei der Respixation leiclit einsehen. Die Mechanils des Athmens lelnt uns die Physiolugie folgendermassen. Die Lungen werden nicht direct durch Muskeh bewegt, sondern sic sind luftdicht in den Thoraxranm eingeschlossen und der 'Thorax wird bewegt. Die indirecte Bewegung der Lungen wird durch ihren luftuichten Einschluss in den Thorax und durch inre Ehaticitat mönlich. Allenthaben liegt die Lunge dem Thorax vollkommen an. Wird der Thorax num ausgedehnt, so muss, da kein luftleerer Raum entstejen kamn und darf, augenblicklich Luft in die Lungen hereinstüzen, welche sich vermöge ilmer Elasticitat ebentalls ansdehnen und dem Thorax sich wieder vollkommen anlegen resp. ihm anliegen bleiben können. Bei einer Exspirationsbowegung fallen die Lumgen nie ganz zusammen, da der Thoraxram bei der Exsurution immer noch grösier ist, als die ganz zusammengefallene Lunge. Die Erweiterung des Thorax in Durchmesser von vorne nach linten und von links nach rechts wird durch die Bewegnng der Rippen, die von oben nach unten dureh das Zwerchfell bewerlsstelligt; die Rippen werden mit dem Brustbein auf der festen Wirbelsäule bewegt. Die Hauptausdehnung des Thoraxraumes geschieht duch don Hauptinspirationsmuskel - das Zwerchfell. Dieses ist in der luhe nach oben gewoibt, bei der tiefsten Inspiration stelit os horizontal. Wem die Inspirationsmuskeh erschlaffen, so fallen die Theile gewöhnlich durch ihre Elasticität und Schwere selbst zusammen, doch ist bei tiefer Exspiration Muskelbewegung in Anspruch genommen. Die Langen bewegen sich in ganz bestimmter Richtung bei 


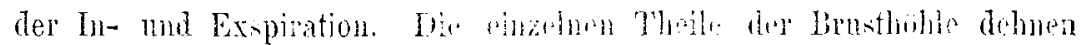

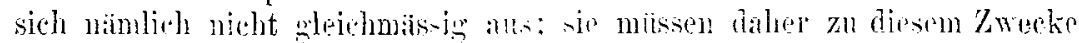

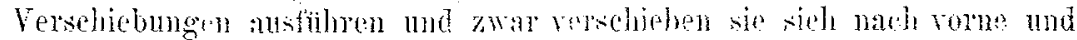

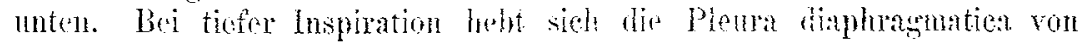
der l'leura costalis ab, dio Lunwers nolunen den dadurch entstancencen Hohlraun ein und schieben sich von der siebenten bis zur elften lipje herab. Ein tiefe Inspiration wird also zur Zeit der Verletzmes nutht statgefunden haben, hierbei wire wohl anch the Lunge vom dem eindringenden Messer setrotfen worden. Trh glanbe sosar, dass naln mit

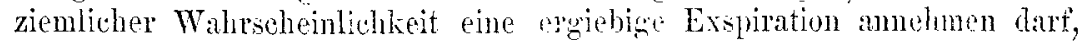
da ja die Terwulung wilurend eines heftigen Wortwechsels stattiand.

Kleinere Zwerchfellswunden sind, ohne Bindringen von Bancheingeweiden, nicht immer tödlich, sie kömnen heilen, jedoch ist wegen geringerer Widerstandsfihigkeit dex Narbe cie Disposition zu einer spätern Hernia diaphragmatica gegeben. Häufiger, namentlich bei etwas bedeutenderer Grösse, vernarbt ter Tundraud ohne Verschluss der Wunduffinung, welche nu durch einen Theil der Leber, der Milz oder des Magens verlegt wird, die Adhäsionen zwikchen diesen Organen und dem Zwerchfell lösen sich aber mit der Zeit wieder nud dann treten, of nach vielen Jahren, plötzlich Tnterleibsorgane in die Brusthöhle, wie nach frischer Verletzung. Der Sectionsbefund des ron mir beobachteten Falles zeigt, dass in gegebonen Falle sofort eine Ferdringung von Baucheingeweiden in die Brusthöhle stattfand, die ejgentiche Incarceration aber erst nach Jahresfrist erfolgte. Die festen Verwachsungen des Netzes mit der Lungenbasis sprechen ganz dentlich dafür, dass sofort nach geschehener Verletzung das betreffende Netzstïek in die Brusthöhle vorfiel. Bei dem geringen Umfange der an ilırem Rande allenthalben vermarbten Zwerchfellsiofinung scheint miv die Annahme unstatthaft, dass auch dus stück Colon transversum sofort nach der Verletzung zugleich nit der Netzpartie in die Brusthohle deplacirt wurde; denn Inearcerationserscheinungen hätten gewiss auftroten müssen. Vielleicht, dass die ein Jahr nach der Verletznng anfgetretene Lnterleibsentzündungs sich auf eine vorübexgehende Einschiebung einer Darmparthie in die Zwerchfellsöftinurg beziehen lässt. Die im Monate Februar beobachteten Incarcerationserscheinnngen lassen sich unzweifelhatt auf den Torfall des Colon transversum in die linke Brusthöhle zurückführen. Besteht im Zwerchfell durch irgend eine Ursache eine abnorme Oeffinung, so ist der in der Brusthöhle beständig herrschende negative Druck, meiner Ansicht nach, die Hauptursache für das Eintreten einer Hernia diaphragmatica; ausserdem finden sich in Dringacte alle Bedingungen zur Erzengung einer Hernia diaphragmatica vereinigt. Gemäss des luftdichten Einschlusses und der Elasticitat der Lungen herrscht in der Brust beständig negativer Luftdruck d. h. es wird auf die in der Brusthöhle selbst liegenden oder sie begrenzenden Organe ein negativer d. I. Saugdruck ausgeubt, welcher die betreffenden Organe in den von den ibermässig ansgedehnten, sich zu verkleinern bestrebten Lungen eingenommenen Raum lineinziehen muss. Bei der Erweiterung des Thorax durch die Inspiration wird die Lunge noch weiter ansgedehnt, der negative Druck im Brustraum wird also noch weiter verstärkt. 


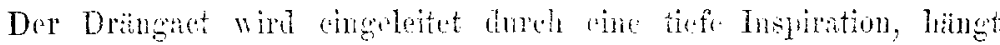
also zusiumen mit ciner Erhöhnng des negativen Druekes im Brustraume. Dise tiefe Inspiration soll dim Ranm in ter Banchlö̈hle verkleinerm durch Herabdrangen des Zwerchtells; Mund nud Nise wird gesehlossen, um den Tiefstand des Zwerediclls einige Zeit zil erhalten, die Bauchmuskeln werden zu Hilte genommen nud nun wird durch den Locus minoris resistentiae Plitz geschalft werden. - In der Lrunkheitsgeschichte wurde bereits mitgetleilt, dass als ursichliehes Monent der Lirkrankung hartnäckige Obstipation angegcben wurie; gewiss ist es nicht unwahrseheinlich, dass heftige Dringrersuche, wem anch vergebens, zu Hülfe genommen wurden, um die lästige Obstipation zu beseitigen, und dadurch die Partie des Colon transversum in die Bristhöhle gedrängt und incarcerirt wurde. Dic mit der Basis der linken Lunge fest verwachsen vorgefundene Netzpartie wird wohl bald nach der Vorletzung durch den negativen Druck der Brtisthöhle während einer tiefen Inspiration fürmlich angesangt worlen sein.

44) J. R., 22 J. alt, ging am 26. Juli $1 S 71$ anf der Abtheilung des Herrn Director Lind w u rm zu mit allgemeinen, unbestimmten Krankheitserscheinnugen. Die Anamnese ergab, dass R. vor etwa zeln Tagen beim Tanzen plötzlich von heftigem Stechen in der linken Seite befallen wurde, in der Gegend der untern, falschen Rippen und zwar in so hohem Grade, dass er nicht mehr allein nach Hause gehen konnte, sondern sich führen lassen musste. Die Respiration war dabei erschwert und sehr schmerzhaft. Auf Einreibungen mit warmen Essig haben sich die Erseheinungen theilwcise vcrloren, wenigstens so grbessert, dass $R$. nach mehreren Tagen in seinem Geschäfte als Schulmacher wieder thätig war. Acht Tage nach diesem ersten Unwohlsein ging $R$. aus and zog sich, wie er angiebt, durch Genuss von Schweinefleisch und Bier eine Indigestion zu. Tags darauf wude er in der Frülue von beftigen Magenschmerzen befallen, Gefühl von Vollsein und leftiges Drücken; Appetitlosigkeit. Nachmittags stellte sich Aufstossen und Erlorechen ein.

Bei der physikalischen Untersuchung zeigte sich anf der rechten Brustseite allenthalben normaler Percussionston und normales Athmen. Links hinten vermindertes Athmen, unten Dämpfung. Milz vergrössert. Herz erschien fast ganz von der Lunge bedeckt. Leber etwas tiefstehend. Der Leib war nicht aufgetrieben, auch nicht besonders empfindlich. Temperatur $36,6^{\circ}$, Puls 128 Schläge. In die Magengegend wurden 4 Blntegel applicirt nud eine Potio Riveri verabreicht.

Die Nacht verbrachte Patient schlaflos mnter beständigem Aufstossen und zeitweisem Erbrechen; dabei konnte er nur anf der linken Seite liegen. Physikalische Untersuchung ergab alle Zeichen eines linkseitigen. Pneumothorax, starke Succussion war vorhanden, das Herz ganz nach rechts verdrängt. Subjectives Gefühl von starker Luftansammlung im Magen. Puls 132.

Am 3. Tage des Spitalaufenthaltes zeigt sich bei der Percussion links vorne oben hell tympanitischer Ton, von der 3. Rippe an. nach abwärts hat man mehr vollen Pereussionston. Die Gegend von der 3. Rippe nach abwärts zeigt sich hervorgetrieben und macht bei der Respiration keine Excursion, während die Partie oberhall der 3. Rippe 
sich bewogt. Rechts Percussion sonor und nomales Athmen. How dimpfung rechts im $1 .-6$. Intercostalranm zwischen Brustwarze nud rechtem Stemalrand. Leber etwas nach abwairts gedrängt. Jinks hinten Precussion tympanitiseh, nach abwïrts gedamplt und kniz ror dem Cebergang in die absolute Milzdimpfing wieder mehr voll und tympanitiseh. Hinten obcu schwache Respiration, welche nach inten ginalich vorsehwindet. Milzgegend hervorgetrieben. Aufstossen und Erbrechen. hält an, durch letzteres werden schwärzliche, blutig gefürbte, flïssige Massen in grosser Menge entlecrt. Jedes Medicament, sowie alle genossenen Speisen and Flïssigkeiten werden sofort wieder orbrochen.

Hält man während des Aufistossens das Ohr an den Brustkorb, so vernimmt man ein Geräusch, das sich nicht besser beschreiben liisst, als Dränsen von Luft aus einem grösseren Hohlraum durch eine enge Oeffinumg hindurch. Succussion ist dentlich bis unter die Achselgrube hin wahrnehmbar. Alle diese Erscheinungen zilsammengenommen, sowie namentlich das Fehlen jedes ursächlichen Momentes für die Erklärung: rines Pnemmothorax, vielleicht auch die Analogie der Symptome mit den Erscheinungen bei einzelnen im Vorstehenden von mir anfgezählten Fällen von Zwerchfellshernien, bestimmen dazu, heute mit aller Bestimmtheit die Diagnose auf eine Verlagerung des Magens in die linke Brusthöhle zu stellen, um so mehr, als dadurch alle Erscheinungen sich ohne Mühe erklären liessen. Nochmals auf das Genaneste examinirt, gab auch hente Patient an, dass er in seinem elften Jahre von einem Wagen überfahren wurde und seitdem öfters an schmerzhaftem Ziehen und Druicken in der Magengegend zu loiden hatte. Auch hatte er öfters das Gefïhl wahrzunehmen geglaubt, als ob der verschluckte Bissen schwer in den Magen käme. Bei dem Anfalle vor zehn Tagen, sagte er jetzt alls, habe er ein Gefïhl wahrgenommen, als ob Etwas von links und unten plötzlich nach oben schlïpfe.

Puls wurde im Verlaufe des Tages schr klein und aussetzend, machte 132 Schläge.

Stuhl war angehalten, ein Klysma erreichte keine Ausleerung. Abends wurde Morphium subcutan injicirt und stellte sich darauf Nachts etwas Schlaf ein.

Andern Tags zeigte sich Patient sehr collabirt. Erbrechen hielt an. Droi diinne, wässerige Ausleerungen erfolgten. Puls wurde immer kleiner, 144 Schläge wurden gezählt. Unter den Erscheinnngen des allgemeinen Collaps verschied Patient Abends 7 Uhr am 28. Juli.

Section. Starker Collajs der Leiche. Aus dem Munde fliesst schwarzbranne, krümliche Flüssigkeit. Unterleib eingezogen, besonders links. Auftreibung der linken Brustseite. Nach Erröffnung des Abdomens, linke Zwerchfellshälfte stark nach abwärts gewölbt, gespannt, unter den falschen lippen hervorragend. Gedärme ziemlich stark contrahirt, auf der linken Seite gegen eine im Zwerchfell fiihlbare Querspalte hinanfgezogen. Die spalte beginnt neben dem Foramen oesophageum und verläuft in einer Länge von 12 Utm. nach rïckwärts und seitlich. Im Unterleib fehlt Magen and Milz; das Duodenum ist in starker Spannung gegen den äussern Spaltwinkel lingezogen, der übrige Raum der Spalte wird von Pankreas mo Netztheilen ansgefüllt. Netztheile begeben sich am 
Colon transversum, welches gegen das $Z$ werchfell angedrïngt ist, theils frei nach abwärts, thcils sind sie in der Spalte festgehalten, theils daselbst verwachsen. Auch die Leber ist durch das Ligamentum hepatoduodenale etwas nach links und mit den linken Lappen nach aufwärts gezogen. Nach Eröfthung der Brust sieht man den Magen ans der linken Brusthöhle heraus gebläht, mit der kleinen Curvatur nach nuten, mit der grossen nach aufwïrts, bis über die 2. Pippe. Rückwärts nach unten findet sich die Milz und daran stossend das Pankreas. Die linke Lunge ist so nach aufwärts comprimirt, dass der linke Bronchus unter einem rechten Winkel geknickt ist; sie füllt nur die Spitze des kegelförmigrn Thoraxraumes aus. Die Lungenbasis bildet eine schiefe von vorn und oben nach rückwärts und unten gerichtete und etwas nach aufwärts gewölbte Ebene. Das Herz mit dem Mediastinum ist nach rechts über das Brustbein hinaus verschoben, liegt auch etwas höher, durch den aufwärts gehobenen linken Leberlappen. Die rechte Lunge ist blutreich, ödematös, besonders im Oberlappen. Die Leber vergrössert, schwarzroth dureh Blutreichthum; Galle schwarzbraun. Der Magen enthält über 3 Mass schwarzbraune, krümliche Flüssigkeit, Magensehleimhaut stark injicirt und aufgewristet, mit reichlichem dicken Schleim belegt. An der hintern Wand sind auch Ekchymosen und linsengrosse, oberflächliche Verschorfungen.

Die Spalte im Zwerchfell beginnt $3 \mathrm{Ctm}$. vom Foramen oesophageum entfernt; ihre Ränder sind gewulstet, glatt, nur nach aussen zu durch angewachsene Netzspangen und Bindegewebsstränge nnregelmässig. Die Bindegewebsstränge gehen atıs vom Colon, der Milz, dem Peritoneum einerseits und der Lungenbasis andererseits und verlaufen theils frei durch die Spalte, theils sind sio damit verwachsen. Der Pylorus liegt innerhalb der Brusthöhle und ist das Anfangsstick des Duodenums in dem äussern Winkel der Spalte incarcerirt, ebenso das Pankreas. Die Section bestätigte also die Diagnose vollständig. Die Zwerchfellsspalte war ohne Zweifel der Effect der vor 11 Jahren stattgehabten Verletzung durch Ueberfahren; die Bindegewebsstränge stellen gewiss den Ansgang und die Ueberbleibsel einer damals eingetretenen Peritonitis und Plenritis dar.

Mit Einschluss der beiden von mir beobachteten Falle konnte icli 44 traumatische Zwerehfellshernien zusammenstellen; 37 Fälle, deren Angaben mir hinlänglich genau und zuverlässig erschienen, wăhlte ich zu folgender tabellarischer Uebersicht aus.

\begin{tabular}{|c|c|c|c|c|}
\hline No. & $\begin{array}{c}\text { Ursache der } \\
\text { Zworehfellshernic. }\end{array}$ & $\begin{array}{l}\text { Art der Zwerehfells- } \\
\text { Wunde. }\end{array}$ & $\left|\begin{array}{c}\text { Zeitraum } \\
\text { zwischen } \\
\text { Verletzung } \\
\text { und Ton. }\end{array}\right|$ & $\begin{array}{c}\text { Eingeweide, welche, und } \\
\text { Brusthühle, in welehe sie } \\
\text { vorficlen. }\end{array}$ \\
\hline 1. & Stichwunde & $\begin{array}{l}\text { Oesophagusöffnung: } \\
\text { erweitert }\end{array}$ & $\begin{array}{l}\text { nicht an- } \\
\text { gegeben }\end{array}$ & $\begin{array}{l}\text { Linker Theil des Magens } \\
\text { mit einem Theil des Duo- } \\
\text { denum und des Colon in } \\
\text { der linken Brusthöhle }\end{array}$ \\
\hline 2. & $\begin{array}{l}\text { Degenstich zwi } \\
\text { schen 4. und } \\
\text { unterster Rippe }\end{array}$ & $\begin{array}{r}\text { Schnittwunt } \\
\text { Zwerchfell von } \\
\text { icher Ansdel }\end{array}$ & 13 Stun- & $\begin{array}{l}\text { Magen mit einem Theile } \\
\text { des Netzes in der linken } \\
\text { Brusthöhle }\end{array}$ \\
\hline
\end{tabular}




\begin{tabular}{|c|c|c|c|c|}
\hline No. & $\begin{array}{l}\text { Ursiche der } \\
\text { Zwerehtelsinirnit }\end{array}$ & $\begin{array}{l}\text { Ar: Aer Zwerchentis-: } \\
\text { Wund }\end{array}$ & 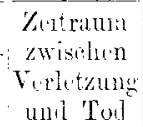 & 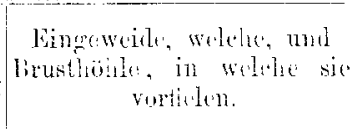 \\
\hline 3. & Stichwunde & $\begin{array}{l}\text { Witten im Zwerel } \\
\text { fell daumberboreite } \\
\text { Wunde }\end{array}$ & : 'lage & $\begin{array}{l}\text { Inagen in der linken Brunt- } \\
\text { hahho }\end{array}$ \\
\hline 4. & Stichwunde & $\begin{array}{l}\text { + Finger breit lange } \\
\text { Wunde im Zwerch- } \\
\text { fell }\end{array}$ & $\begin{array}{l}3 \text { litere } \\
\text { und } \\
3 \text { Stamiden }\end{array}$ & $\begin{array}{l}\text { Magen, Pankeas, Neta } \\
\text { mad Colon in der linken } \\
\text { Brustholle }\end{array}$ \\
\hline 5. & $\begin{array}{l}\text { Messerstich in } 4 . \\
\text { linken Intercostal- } \\
\text { rumm }\end{array}$ & $\begin{array}{l}\text { Zwerchfellswunde } \\
\text { ansserst eng }\end{array}$ & 9 Tage & $\begin{array}{l}\text { Die diinnen Gedlüme in } \\
\text { der liuken Brustböhle }\end{array}$ \\
\hline 6. & $\begin{array}{l}\text { Stich zwischen } \\
\text { letzter wahrer und } \\
\text { erster falscherRippe } \\
\text { links }\end{array}$ & $\begin{array}{l}\text { Oben in } \\
\text { Seite de } \\
\text { fells Oeff }\end{array}$ & 3 Monate & $\begin{array}{l}\text { Netz in der linken Brust- } \\
\text { höhle mit der Wunde ver- } \\
\text { wachsen }\end{array}$ \\
\hline 7. & Stichwunde & $\begin{array}{l}\text { Zwer } \\
\text { spitzer W } \\
\text { bohrt }\end{array}$ & 3 Monate & $\begin{array}{l}\text { Magen eingeklemmt in } \\
\text { der linken Brustliöle }\end{array}$ \\
\hline 8. & $\begin{array}{l}\text { Schwertstoss in den } \\
\text { 4. Intercostalraum }\end{array}$ & $\begin{array}{l}\text { Wunde in seh } \\
\text { Theile des Zw } \\
\text { tells }\end{array}$ & 5 Monate & $\begin{array}{l}\text { Magen, Netz und Pankieas } \\
\text { in der linken Brusthöhle }\end{array}$ \\
\hline 9. & $\begin{array}{l}\text { Schief nach ab- } \\
\text { wärts dringender } \\
\text { Stich in den } 6 . \text { In- } \\
\text { tercostalraum }\end{array}$ & $-\mid \begin{array}{c}2 \text { Finger breite } \\
\text { Wunde im fleischi- } \\
\text { gen Theil des } \\
\text { Zwerchfells links }\end{array}$ & 11 Monate & $\begin{array}{l}\text { um, grösster Theil } \\
\text { am und Colon trans- } \\
\text { und Netz in der } \\
\text { Brusthöhle }\end{array}$ \\
\hline 10. & Stichwunde & $\begin{array}{c}\text { Kleinfinger-breite } \\
\text { Wunde im fleischi- } \\
\text { gen Theil des } \\
\text { Zwerchfells }\end{array}$ & 8 Monate & $\begin{array}{l}\text { Grosser Theil des Colon } \\
\text { in der linken Brusthöhle }\end{array}$ \\
\hline 11. & $\begin{array}{l}\text { Messerstich in die } \\
\text { Brust }\end{array}$ & Stichwunde & $\begin{array}{l}48 \text { Stun- } \\
\text { den }\end{array}$ & int in \\
\hline 12. & $\begin{array}{l}\text { Stichwunde in den } \\
\text { Ruicken }\end{array}$ & $\begin{array}{l}\text { Nahe der Wirbel- } \\
\text { säule Oeffnung mit } \\
\text { vulstigen Rindern }\end{array}$ & $\begin{array}{l}\text { unbe- } \\
\text { stimmt }\end{array}$ & $\begin{array}{l}9 \text { Fuss des Dïnndarmes } \\
\text { in der lirken Brusthöhle }\end{array}$ \\
\hline 13. & $\begin{array}{c}\text { Stich in den 9. lin- } \\
\text { ken Intercostalraum }\end{array}$ & $\begin{array}{c}\text { Drei Fingerspitzen } \\
\text { weite Oeffnung }\end{array}$ & 15 Monate & $\begin{array}{l}\text { n transversum } \\
\text { setz in der } \\
\text { thöhle }\end{array}$ \\
\hline 14. & $\begin{array}{r}\text { Sturz in ein Messer. } \\
\text { das unter der linken } \\
\text { Brust tief eindrang }\end{array}$ & Nicht angegeben & 20 Jahre & $\begin{array}{l}\text { Eine Schlinge des Colon } \\
\text { transversum in linkerBrust- } \\
\text { böhle }\end{array}$ \\
\hline 15. & $\begin{array}{l}\text { Penetrirende Brust- } \\
\text { wunde }\end{array}$ & Nicht angegeben & I Jahr & $\begin{array}{l}\text { Einklemmung batte lin- } \\
\text { kerseits statt }\end{array}$ \\
\hline 16. & $\begin{array}{l}\text { Stich in den } 8 \\
\text { linken Intercostal- } \\
\text { raum }\end{array}$ & $\begin{array}{l}\text { Eine fiir } 3 \text { Finger } \\
\text { durchgängige Oeff- } \\
\text { nung }\end{array}$ & 12 Jahre & $\begin{array}{l}\text { Theil des Colon trans- } \\
\text { cersum und des Omentum } \\
\text { in der linken Brusthöhle }\end{array}$ \\
\hline 17. & $\begin{array}{l}\text { Messerstich in die } \\
\text { linke Seite; ein Netz- } \\
\text { stiick fiel zuräussern } \\
\text { Wunde vor }\end{array}$ & Kleine Wunde & 11 Tage & $\begin{array}{l}\text { Magen eingeklemmt } \\
\text { der linken Brusthöhle }\end{array}$ \\
\hline
\end{tabular}




\begin{tabular}{|c|c|c|c|c|}
\hline No. & $\begin{array}{l}\text { Crsache der } \\
\text { Zwerebtellshome }\end{array}$ & $\left\{\begin{array}{l}\text { Art der Zwerehtiolls- } \\
\text { Whande }\end{array}\right.$ & $\left|\begin{array}{c}\text { Zeitrinum } \\
\text { zwischen } \\
\text { Fortetzung } \\
\text { und Tor }\end{array}\right|$ & $\begin{array}{l}\text { Dingeweide, woichi, und } \\
\text { lirmsthioble, in wolche sie } \\
\text { vorticlen }\end{array}$ \\
\hline 13. & $\begin{array}{l}\text { Wehrere Messer- } \\
\text { stiche in die linket } \\
\text { Suite }\end{array}$ & $\begin{array}{l}\text { 2 Oeftumngen, durch } \\
\text { deren eine jedoch } \\
\text { nur Eingeweide ror- } \\
\text { ficlen }\end{array}$ & 5 Tage & $\begin{array}{l}\text { Gronser Theil des colon } \\
\text { transversum in der linken } \\
\text { Brnstlöhle }\end{array}$ \\
\hline 19. & $\begin{array}{l}\text { Stich in den 5. } \\
\text { linken Intercostal- } \\
\text { raum; Selbstmord- } \\
\text { versuch }\end{array}$ & $\begin{array}{l}\text { Fiir } 2 \text { Finger } \\
\text { saingige Ocfi }\end{array}$ & \& Jaline & $\begin{array}{l}\text { Grosser Theil des Colon } \\
\text { transversum, das grosse } \\
\text { Netz and Abschnitte des } \\
\text { Ileum in der linken Brust- } \\
\text { löhle }\end{array}$ \\
\hline 20. & $\begin{array}{l}\text { PenetrirendeBauch- } \\
\text { wunde }\end{array}$ & $\begin{array}{c}\text { Scharf geschnittene } \\
\text { Wunde }\end{array}$ & $\begin{array}{c}1+\text { Stun- } \\
\text { den }\end{array}$ & $\begin{array}{l}\text { Der verletzte Magenfun- } \\
\text { dus in der linken Brust- } \\
\text { höhle }\end{array}$ \\
\hline 21. & $\begin{array}{l}\text { Messerstich in den } \\
\text { linken } 8 \text {. Intercostal- } \\
\text { paum }\end{array}$ & $\begin{array}{l}\text { Halbguldengrosse } \\
\text { Oeffung in Mitte } \\
\text { der linken Zwereh- } \\
\text { fellpartie }\end{array}$ & $1 \%$ Jahrs & $\begin{array}{l}\text { (i Zoll vom Colon trans- } \\
\text { versum und eine Partie } \\
\text { des grossen Netzes in der } \\
\text { linken Brusthöhle }\end{array}$ \\
\hline 22 . & $\begin{array}{l}\text { Schuss in die linke } \\
\text { Brust }\end{array}$ & $\begin{array}{l}3-4 \text { Lra } \\
\text { ter Riss i } \\
\text { Theil }\end{array}$ & $\begin{array}{l}\text { Mehrere } \\
\text { Stunden }\end{array}$ & $\begin{array}{l}\text { Magen mit dem grossen } \\
\text { Netz in der linken Brust- } \\
\text { höle }\end{array}$ \\
\hline 23 & $\begin{array}{l}\text { Schuss durch Carti- } \\
\text { litgo xiphoidea }\end{array}$ & $\begin{array}{l}\text { Fingerbr } \\
\text { nung }\end{array}$ & 8 Monate & Colon in linker Brusthöble \\
\hline 24 & $\begin{array}{l}\text { Sehuss vou Minié- } \\
\text { kugel }\end{array}$ & Nicht beschrieben & $\begin{array}{l}\text { unbe- } \\
\text { stimmt }\end{array}$ & $\begin{array}{l}\text { d Duodenum, } \\
\text { heinlich in lin- } \\
\text { hle }\end{array}$ \\
\hline 25. & $\begin{array}{l}\text { Verschïttung, meh- } \\
\text { rere Rippenbrüche }\end{array}$ & $\begin{array}{l}\text { Aut der linken Seite } \\
\text { des Zwerchtells Riss } \\
\text { yon 1/2 Daumen } \\
\text { Breite }\end{array}$ & $\begin{array}{l}\text { Nicht an- } \\
\text { gegeben }\end{array}$ & $\begin{array}{l}\text { Magen, Colon und Netz } \\
\text { in der linken Brusthöhle }\end{array}$ \\
\hline 26. & $\begin{array}{c}\text { Sturz } \\
\text { herab }\end{array}$ & $\begin{array}{l}\text { Spalte im linken } \\
\text { Theil des Zwerch- } \\
\text { fells, daumenbreit }\end{array}$ & 2 Tage & $\begin{array}{l}\text { Ein Theil des Magens in } \\
\text { der linken Brusthöhle }\end{array}$ \\
\hline 27. & $\begin{array}{l}\text { Sturz ron bedeu- } \\
\text { tender liöhe herab }\end{array}$ & $\begin{array}{c}\text { Line ansehuliche } \\
\text { Spalte im sehnigen } \\
\text { Mittelpunkt des } \\
\text { Zwerchfells }\end{array}$ & 1 Jahr & $\begin{array}{l}\text { Eine Partie des Colon } \\
\text { und fast das ganze Netz, } \\
\text { sowie der sehr ausgedehnte } \\
\text { Hagen in der linken Brust- } \\
\text { höhle }\end{array}$ \\
\hline 28. & $\begin{array}{l}\text { Mehrere Rippen- } \\
\text { fracturen der rech- } \\
\text { ten Seite }\end{array}$ & $\begin{array}{l}\text { Ein querliegendes } \\
\text { längliches Loch im } \\
\text { rechen Theile des } \\
\text { Zwerchfells }\end{array}$ & 2 Jahre & $\begin{array}{l}\text { Das ganze Netz und eine } \\
\text { Partie des Colon, wahr- } \\
\text { scheinlich in der rechten } \\
\text { Brusthöhle }\end{array}$ \\
\hline 29. & $\begin{array}{l}\text { Sturz yon einem } \\
\text { Thurm, Fraetrr der } \\
\text { sieben untern linken } \\
\text { Rippen bei einem } \\
\text { spiten Falle }\end{array}$ & 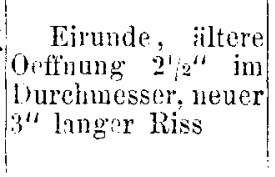 & $\begin{array}{c}15 \text { Jalire } \\
\text { resp. } \\
4 \text { T'age }\end{array}$ & $\begin{array}{l}\text { Magen,Colon transversum } \\
\text { und weitere Partie des } \\
\text { Colon in der linken Brust- } \\
\text { böhle }\end{array}$ \\
\hline
\end{tabular}




\begin{tabular}{|c|c|c|c|c|}
\hline No. & 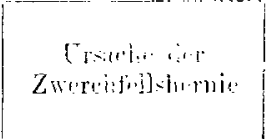 & 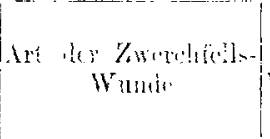 & 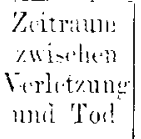 & 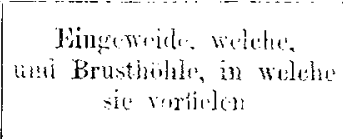 \\
\hline io. & $\begin{array}{l}\text { Sturz von der llöhe } \\
\text { zwejer Stockworke }\end{array}$ & $\begin{array}{l}\text { Einc ovalo Geftuung } \\
\text { im rechten Theil des } \\
\text { Zwerchfells, mrelir } \\
\text { nach rorne: } 2 \text { Zoll } \\
\text { lang }\end{array}$ & 20 Jahre: & $\begin{array}{l}\text { Wheil von loudenum, der } \\
\text { grijsste Theil des lleum, } \\
\text { eine Partic colon mit } \\
\text { eigenthimlichem Leber- } \\
\text { fortsatze in der rechten } \\
\text { Brusthöhle }\end{array}$ \\
\hline 31. & $\begin{array}{l}\text { Fractur der ti. rech } \\
\text { ten lippe }\end{array}$ & $\begin{array}{l}\text { Oeffinung im rech- } \\
\text { tert sohnget Theil } \\
\text { des Zwerchfells } 11.2 \\
\text { Zoll im Durchimesser }\end{array}$ & $\begin{array}{l}\text { unbe- } \\
\text { stimmt }\end{array}$ & $\begin{array}{l}\text { Colon transyersum in der } \\
\text { rechten brusthöle }\end{array}$ \\
\hline 32. & $\begin{array}{l}\text { Verschiittung; Frac- } \\
\text { tur der 5. rechten. } \\
\text { Rippe }\end{array}$ & $\begin{array}{l}\text { Riss von rechts } \\
\text { hinten nach links } \\
\text { vorne; } 20 \text { Ctm. lang }\end{array}$ & & $\begin{array}{l}\text { Grösster Theil des Dick- } \\
\text { darms und der rechte } \\
\text { Leberlappen in der rechten } \\
\text { Brusthöhle }\end{array}$ \\
\hline 33. & $\begin{array}{l}\text { Starke Anstreng- } \\
\text { ung bei einer Rau- } \\
\text { terei }\end{array}$ & $\begin{array}{l}\text { Oesophagusöffnung: } \\
\text { um } 10 \mathrm{Ctm} \text {. erweitert }\end{array}$ & $\begin{array}{l}\text { Wenige } \\
\text { Tage }\end{array}$ & $\begin{array}{l}\text { Netz, Colon transversum, } \\
\text { Milz und Magen in der } \\
\text { linken Brusthöhle }\end{array}$ \\
\hline 34. & $\begin{array}{l}\text { Fall auf dem lise } \\
\text { sehr forcirte Dreh- } \\
\text { bewegung }\end{array}$ & $\begin{array}{l}\text { Grosse, vernarbte, } \\
\text { Oeffnung; ein 1" } \\
\text { langer, frischer Riss }\end{array}$ & $\begin{array}{l}2 \text { Jahre } \\
\text { resp. } 51 \\
\text { Stunden }\end{array}$ & $\begin{array}{l}\text { Magen, grosses Netz, } \\
10-12^{\prime \prime} \text { des Colon trans- } \\
\text { versum und die Milz in } \\
\text { der linken Brusthöle }\end{array}$ \\
\hline 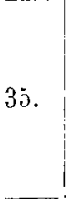 & $\begin{array}{l}\text { Fractur des 1. und } \\
\text { 5. Lendenwirbels u. } \\
\text { des Kreuzbeins } \\
\text { durch Verschiittung }\end{array}$ & $\begin{array}{l}\text { Linksseitig im } \\
\text { Zwerchfell eine } \\
\text { mannsfaustgrosse } \\
\text { Oeffuung }\end{array}$ & \& Wochen & $\begin{array}{l}\text { Magen, ein Theil des Colon } \\
\text { transversum, die obcrn } \\
2 \text { Drittheile des Dünn- } \\
\text { darms und die obere Spitze } \\
\text { der Milz in der linken } \\
\text { Brusthöhle }\end{array}$ \\
\hline 36. & Verschittung & $\begin{array}{l}\text { Risswunde im rech- } \\
\text { ten Theile des } \\
\text { Zwerchfells }\end{array}$ & 22 Tage & $\begin{array}{l}\text { Die Leber lag mit ihrem } \\
\text { rechten Lappen und zwar } \\
\text { vollig verdreht in cler } \\
\text { rechten Brusthïle }\end{array}$ \\
\hline 37. & Ueberfahren & $\begin{array}{l}\text { Spalt im Zwerch- } \\
\text { fell } 3 \mathrm{Ctm} \text {. vom Fo- } \\
\text { ramen oesophageum } \\
\text { entfernt beginnend } \\
\text { und in Lïnge von } \\
\text { 12 Ctm. nach rick- } \\
\text { wärts und seitlich } \\
\text { verlaufend }\end{array}$ & 1 Jahre & $\begin{array}{l}\text { Magen, Milz und Pankieas } \\
\text { in der linken Brusthöhle }\end{array}$ \\
\hline
\end{tabular}

Höchst selten entsteht der an sich nicht häufig zur Beobachtung kommende Zwerehfellsbruch, indem Baucheingeweide durch den Hiatus oesophageus emporsteigen. Fast alle vorliegenden Beobachtungen beziehen sich vielmehr auf Hernien, dic durch angeborne oder zufällig - in Folge von Verletzungen - entstandene Spalten in der linken Hälfte des Zwerchfells emporgestiegen sind; aut der 
rechten Seite verdeckt die Leber solche Oeffnungen des Zwerehfells, wenn sie nicht sehr gross sind. In der Regel ist also dem Zwerchfellsbruche eine penctrirende Brustwunde oder eine bedeutende Quetschung der linken Seite, eine Erschiitterung durch Fall von bedeutender Höhe oder eine Zersprengung des Zwerchfells durch übermässige Anstrengung der Bauchpresse vorhergegangen. Gewöhnlich hat man die dislocirten Baucheingeweide, am häufigsten Magen, Quergrimmdarm und Netz, ganz unbedeckt in der Brusthöhle gefunden. Seltener waren sie von einem einfachen, noch seltener von einem doppelten, serösen Ueberzuge (Bruchsack), der ibnen von dem Peritoneum oder von der Pleura, oder endlich von beiden gemeinschaftlich geliefert wurde, überzogen. Dies hängt, wie man leicht einsieht, davon ab, ob bei der Entstehung der Spalte im Zwerchfell die beiden serösen Häute oder nur eine von ihnen oder endlich gar keine unversehrt geblieben sind. Aus dem Raume, welchen die Baucheingeweide nunmehr in Thorax einnehmen, müssen die Brusteingeweide natürlich verdrängt werden; zunächst wird die Lunge comprimirt; bei bedeutenderer Grösse des Bruches auch das Herz verschoben.

In den von mir zusammengestellten 37 Fällen von Zwerchfellshernien war die veranlassende Ursache 21 mal durch Stichverletzungen; 3 mal durch Schusswunden; 10 mal durch Sturz und Verschuttung, theils mit, theils ohne Rippenfractur; 1 mal durch starke Anstrengung; 1 mal durch Fall resp. starke Drehbewegung; endlich 1 mal durch Ueberfahren gegeben. Die abnorm erweiterte Oesophagusöffnung diente den Baucheingeweiden 2 mal zum Durchtritt in die Brusthöhle. 5 mal fanden sich die dislocirten Baucheingeweide in der rechten, $32 \mathrm{mal}$ in der linken Brusthöhle. Ein eigentlicher Bruchsack, von Pleura oder Peritoneum gebildet, wurde in keinem der oben zusammengestellten Fälle beobachtet. Der Zeitraum, welcher zwischen der ursächlichen Verletzung und dem meist durch Incarceration bedingten Tode verstrich, betrug in dem am raschesten verlaufenden Falle wenige Stunden, während zweimal der Zustand 20 Jahre lang ertragen wurde.

Auch bei der sorgfältigsten Untersuchung, sagt Bardeleben, wird die Diagnose eines $Z_{w}$ erchfellbruches nicht mit Sicherheit gestellt werden können. Wir besitzen kein Mittel, fährt er fort, um die Reposition oder gar die Retention eines solchen Bruches zu bewirken und vermögen gegen die relativ häufigen Einklemmungen dieser Brüche auch nur mit den bei inneren Einklemmungen über- 
haupt angewandten Mitteh - vorausichtlich olne Erfugr - anzukämpłen.

Ganz entgegengesetzt spricht sich Bochilalek am Schlusse einer Abhandlung uber Zworehfellshernicn in folgenden sitzen aus.

1) Es ist weler dic anguborne, noth weniger die erworbene Zwerehfelsheruic unter allen Umständen tödtlich. Beim erworbenen Bruch werden die Chancen fuir die Erhaltung des Lebens des Betreffenden um so ginstiger sein, je langsamer der Bruch cntsteht, resp. je langsaner und je weniger sich die Bancheingeweide in die Brusthöhle hineindrïngen und je weniger sonst schwere Complicationen mit demselben verbunden vorkommen.

2) Die Diagnose der Zwerchfellshernie lïsst sich bei Anwendung der houtzutage zu Gebote stchenden Mittel, der Auseultation und der Percussion, bei richtiger Beurtheilung der Ursachen, welche - bei erworbenen Hernien - eine Continuitätstrennung des Zwerchfells hervorzubringen im Stande sind, und mit Berücksichtigung der andern Brustsymptome, wenigstens mit mehr oder weniger grosser Wahrscheinlichkeit feststellen.

3) In Betreff der Therapie der Zwerchfellshernien könnte es vielfach angezeigt sein, nach festgestellter Erkenntniss der letztern einen operativen Eingriff nach L a ennee's Vorschlag und Angabe zu versuchen; nänlich die Bauchdecken so weit einzuschneiden, dass man in die Wunde zwei Finger einbringen und mit denselben dic Eingeweide in die Unterleibshöhle berabziehen könnte uud dann die Retention der ersteren durch fortgesetzte aufrechte Stellung und Hungerleiden zu erhalten. Der Beachtung, meint Bochdalek, sei dieser Vorschlag um so mehr werth, als einer solchen Operation auch ron anatomischem Standpunkte aus kein bedenkliches Hinderniss im Wege steht.

Guthrie hat in seinen Commentarien die Mögliehkeit einer Hernie durch das Zwerchfell nach Schussverletzung vorhergesagt und die Operation beschrieben, welche zu deren Reposition versucht werden könnte, nämlich eine Incision durch die Bauchwand, gross genug, dass die Hand eindringen und den Magen wieder in die rechte Lage bringen könntc.

Weder Bardeleben's noch Bochdalek's Darstellung scheint mir vollständig begründet. B ardeleb en geht sicher zu weit, wenn er die Diagnose einer Zwerchfellshernie fast als Unmöglichkeit hinstellt, dem es sind wohl Fälle denkhar, ja in No. 44 konnte ich selbst einen Fall auffihlen, bei welchem mit Hïlfe der Anamnese und namentlich der Auscultation und Percussion die Diagnose fast 
ganz sicher gestellt werten konnte. Besondere Beriicksiehtigung verdient, dass Erseheinungen gleichzeitig in Bauchhöhle und Brusthöhle auftreten und eine genaue Wuirdigung derselben wird wohl in einzehen Fïllen, namentlich bei Vorlagerung des Magens in die Brustlıölile, die Diagnose einer Hernia diaphragmatica gestatten.

Mit Bochdalek's Sätzen möchte ich mich deshalb nicht gänzlich cinverstanden erklären, weil mir seine Ansicht, dass der Ausführung der Operation nach Laennee's Methode vom anatomischen Standpunkt aus kein bedenkliches Hinderniss im Wege stehe, und deshalb der Vorschlag Laennec's um so mehr Beachtung verdiene, eben zu sehr anatomisch scheint, als dass sie in der Praxis Geltung. erlangen könnte. Wer mehrfach Gelegenheit hatte, Laparotomieen, zu iroend welchem Zwecke ausgeführt, in ihrem klinischen Verlaufe zu beobachten, wird ilıre Gefahren nicht unterschätzen, und wird sich nicht leicht bei einer nur wahrseheinlichen Diagnose zu einer lebensgefährlichen Operation entschliessen, deren Erfolg, selbst für den Fall, dass die Operation selbst gut verläuft, sehr fraglich ist. Gewiss ist stets der Erfolg zweifelhaft im höchsten Grade, denn es giebt kein Mittel, für die Dauer eine Wiedereinklemmung zu verhüten, falls auch zunächst längeres Hungerleiden und aufrechte Stellung den Erfolg der Operation sichern wollten. Trotzdem müchte ich die Operation nicht ganz verwerfen, sie wird stets als ultimum refugium mit um so grösserem Rechte dienen müssen, als selbst im Falle einer unriehtigen Diagnose die Laparotomie ihre Berechtigung hat. Die innere Einklemmung als solche könnte wohl nur in ihren Syinptomen allein mit einer eingeklemmten Zwerchfellshernie verwechselt werden und sie wird stets auffordern, als letztes Mittel zur Hebung der Einklemmung die Laparotomie vorzunehmen.

Ein Experiment, welches ich öfter von meinem Chef Professor von Nussbaum ausführen sah, könnte uns vièlleicht die Mittel in die Hand geben, in zweifelbaften Fällen die Diagnose zu sichern, ja selbst hie und da die bestehende Einklemmung zu heben. Wiederholt hatte ich Gelegenheit, mich zu ïberzeugen, dass eine während tiefer Chloroformnarkose durch den Anus eingeführte Hand im Mastdarm derart vordringen kann, dass sich die Fingerspitzen unmittelbar unterhalb des schwertförmigen Fortsatzes des Sternums durch die Bauchdecken hindurch ganz deutlich abgreifen lassen. Ist die Hand nicht ubermässig stark entwickelt und die Chloroformnarkose so tief, dass die Sphinkteren, gehörig erschlaffit, kein zu hartnäckiges Hinderniss abgeben, so steht dieser Manipulation nicht 
die geringste Schwierigkeit in der Ausfuhrung entgegen, zumal, wenn die vorher gut eingeölte Hand vorsichtig unter leichten Drehbewegungen allmälig in dic Höhe ggeschoben wird.

Ich habe mich mit eigner Hand davon iiberzeugt, dass sich Prof. von Nussbaum's Hand im Unterleibe an der Spitze des Sternums einer tief narkotisirten Frau hin und her bewegte.

Anhaltspunkte zur Art und Weise, eine allenfalls vorhandene innere Einklemmung mit der auf die eben beschriebene Weise eingefiihrten Hand zu lösen, lassen sich wohl nicht einmal im Allgemeinen geben, aber dennoch wäre es wohl zu versuchen, durch schiebende oder ziehende Bewegungen die dislocirten oder verschlungenen Darmpartien wieder in normale Verhältnisse zu bringen. 